\title{
Three Delayed Critical 15 in. Diameter Interacting Enriched (93.14) Uranium Metal Cylinders Without Moderator and Reflector
}

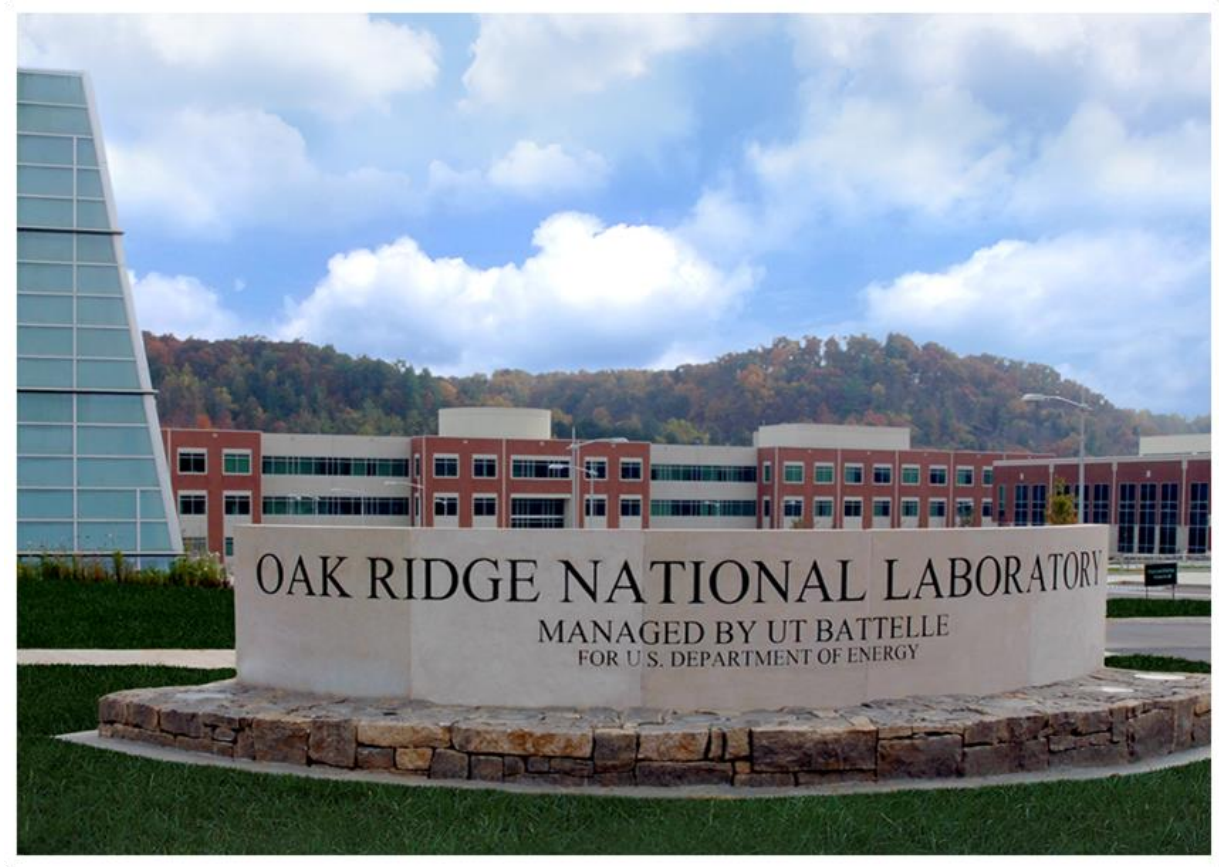

Approved for public release.

Distribution is unlimited

John T. Mihalczo

December 2020 


\title{
DOCUMENT AVAILABILITY
}

Reports produced after January 1, 1996, are generally available free via US Department of Energy (DOE) SciTech Connect.

Website www.osti.gov

Reports produced before January 1, 1996, may be purchased by members of the public from the following source:

\author{
National Technical Information Service \\ 5285 Port Royal Road \\ Springfield, VA 22161 \\ Telephone 703-605-6000 (1-800-553-6847) \\ TDD 703-487-4639 \\ Fax 703-605-6900 \\ E-mail info@ntis.gov \\ Website http://classic.ntis.gov/
}

Reports are available to DOE employees, DOE contractors, Energy Technology Data Exchange representatives, and International Nuclear Information System representatives from the following source:

Office of Scientific and Technical Information

PO Box 62

Oak Ridge, TN 37831

Telephone 865-576-8401

Fax 865-576-5728

E-mail reports@osti.gov

Website http://www.osti.gov/contact.html

This report was prepared as an account of work sponsored by an agency of the United States Government. Neither the United States Government nor any agency thereof, nor any of their employees, makes any warranty, express or implied, or assumes any legal liability or responsibility for the accuracy, completeness, or usefulness of any information, apparatus, product, or process disclosed, or represents that its use would not infringe privately owned rights. Reference herein to any specific commercial product, process, or service by trade name, trademark, manufacturer, or otherwise, does not necessarily constitute or imply its endorsement, recommendation, or favoring by the United States Government or any agency thereof. The views and opinions of authors expressed herein do not necessarily state or reflect those of the United States Government or any agency thereof. 
Isotope and Fuel Cycle Technology Division

\title{
THREE DELAYED CRITICAL 15 IN. DIAMETER INTERACTING ENRICHED (93.14) URANIUM METAL CYLINDERS WITHOUT MODERATOR AND REFLECTOR
}

\author{
John T. Mihalczo
}

December 2020

\author{
Prepared by \\ OAK RIDGE NATIONAL LABORATORY \\ Oak Ridge, TN 37831-6283 \\ managed by \\ UT-BATTELLE, LLC \\ for the \\ US DEPARTMENT OF ENERGY \\ under contract DE-AC05-00OR22725
}





\section{CONTENTS}

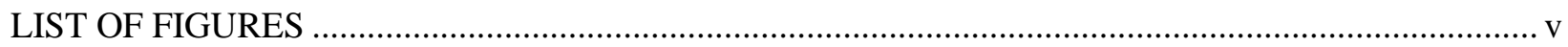

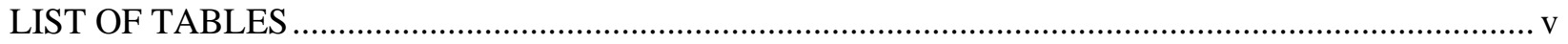

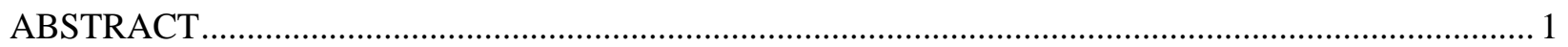

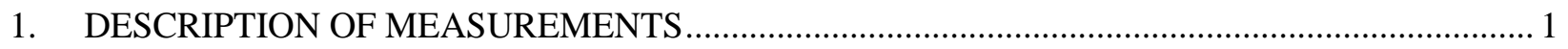

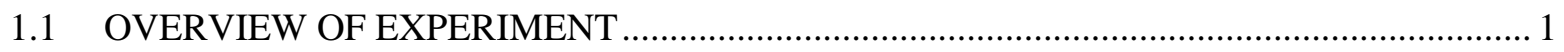

1.2 DESCRIPTION OF EXPERIMENTAL CONFIGURATION …......................................... 2

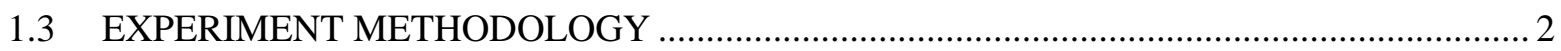

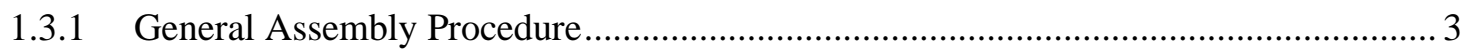

1.3.2 Lateral Alignment of the Lower Section with the Middle Section .............................. 6

1.3.3 Lateral Alignment of the Middle Section with the Lower Section ................................ 6

1.3.4 Lateral Alignment of the Middle Section with the Upper Section................................ 7

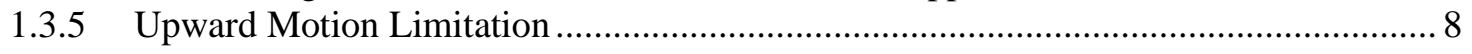

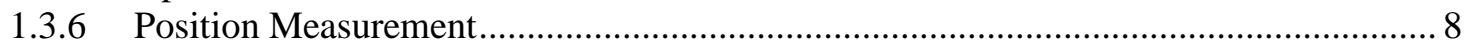

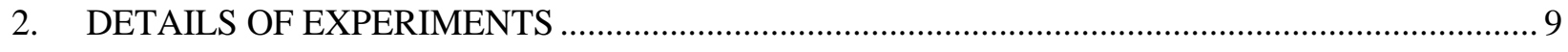

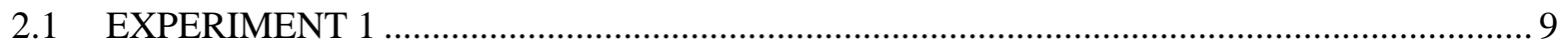

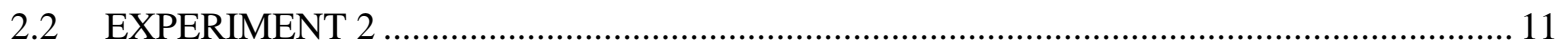

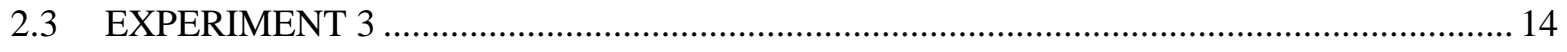

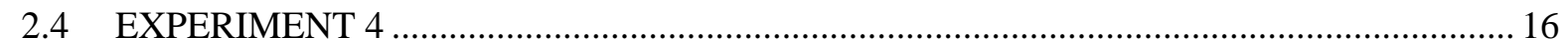

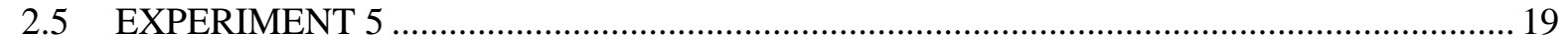

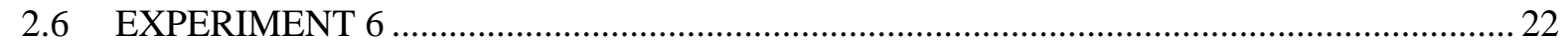

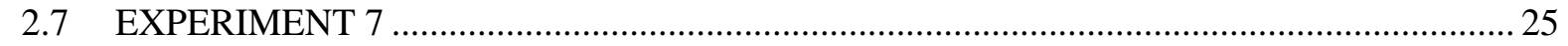

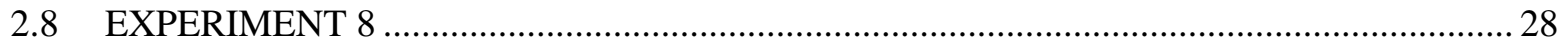

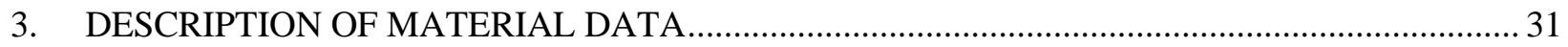

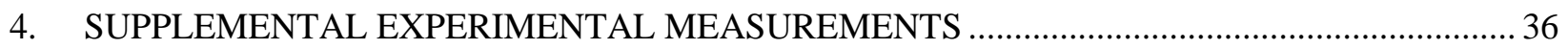

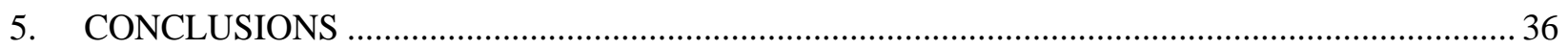

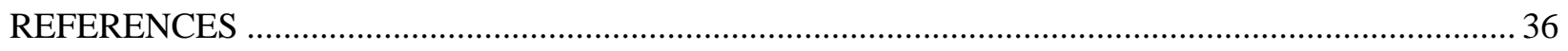

APPENDIX A. SUPPORT STRUCTURE ……..................................................................... A-1

APPENDIX B. UNCERTAINTIES IN MATERIALS PROVIDED BY THE Y-12 NSC ..................... B-1 



\section{LIST OF FIGURES}

Figure 1. Photograph of the vertical assembly machine with the movable table up................................. 4

Figure 2. Three interacting 15 in. diameter, 2 in. thick uranium metal cylinders with the lower

cylinder on the support stand in the down position. ................................................................ 5

Figure. 3. Sketch of the fixture for lateral alignment of uranium metal cylinders.................................... 8

Figure 4. Experiment 1 - Configuration of delayed critical unreflected, unmoderated uranium

$\left(93.14\right.$ wt. $\left.\%{ }^{235} \mathrm{U}\right)$ metal 15 in. diameter three interacting cylinders with a nominal height

of $1.125 \mathrm{in}$.

Figure 5. Experiment 2-Configuration of delayed critical unreflected, unmoderated uranium

(93.14 wt.\% $\left.{ }^{235} \mathrm{U}\right)$ metal 15 in. diameter three interacting cylinders with nominal height of $1.25 \mathrm{in}$.

Figure 6. Experiment 3 - Configuration of delayed critical unreflected, unmoderated uranium

(93.14 wt.\% ${ }^{235} \mathrm{U}$ ) metal $15 \mathrm{in}$. diameter three interacting cylinders with a nominal height of $1.375 \mathrm{in}$.

Figure 7. Experiment 4 - Configuration of delayed critical unreflected, unmoderated uranium (93.14 wt.\% $\left.{ }^{235} \mathrm{U}\right)$ metal 15 in. diameter three interacting cylinders with nominal height of $1.5 \mathrm{in}$.

Figure 8. Experiment 5-Configuration of delayed critical unreflected, unmoderated uranium (93.14 wt. $\left.\%{ }^{235} \mathrm{U}\right)$ metal 15 in. diameter three interacting cylinders with nominal height of 1.625 in.

Figure 9. Experiment 6-Configuration of delayed critical unreflected, unmoderated uranium (93.14 wt.\% $\left.{ }^{235} \mathrm{U}\right)$ metal 15 in. diameter three interacting cylinders with a nominal height of $1.75 \mathrm{in}$.

Figure 10. Experiment 7-Configuration of delayed critical unreflected, unmoderated uranium (93.14 wt.\% $\left.{ }^{235} \mathrm{U}\right)$ metal 15 in. diameter three interacting cylinders with a nominal height of $1.875 \mathrm{in}$.

Figure 11. Experiment 8--Configuration of delayed critical unreflected, unmoderated uranium $\left(93.14\right.$ wt.\% $\left.{ }^{235} \mathrm{U}\right)$ metal $15 \mathrm{in}$. diameter three interacting cylinders with nominal height of $2.0 \mathrm{in}$.

\section{LIST OF TABLES}

Table 1. Summary of cylinder thicknesses, cylinder masses, and measured separations, and experimental $\mathrm{k}_{\text {eff }}$ for delayed critical experiments with three interacting cylinders of 15 in. diameter uranium metal cylinders.

Table 2. Measured height of each radial increment, sum of inspection report heights, and average gap between parts of each radial section for experiment 1 with three interacting $15 \mathrm{in.} \mathrm{OD}$ cylinders that are $1.125 \mathrm{in}$. high.

Table 3. Summary of configurations and neutron multiplication factors for experiment 1 .

Table 4. Measured height of each radial increment, sum of inspection report heights and average gap between parts of each radial section for experiment 2 with three interacting $15 \mathrm{in.} \mathrm{OD}$ cylinders that are 1.25 in. high.

Table 5. Summary of configurations and neutron multiplication factors for experiment 2.

Table 6. Measured height of each radial increment, sum of inspection report heights, and average gap between parts of each radial section for experiment 3 with three interacting $15 \mathrm{in.}$ OD cylinders that are 1.375 in. high.

Error! Bookmark not defined. 
Table 7. Summary of configurations and neutron multiplication factors for experiment 3

Table 8. Measured height of each radial increment, sum of inspection report heights, and average gap between parts of each radial section for experiment 4 with three interacting $15 \mathrm{in}$. OD cylinders that are $1.5 \mathrm{in}$. high.

Table 9. Summary of configurations and neutron multiplication factors for experiment 4.

Table 10. Measured height of each radial increment, sum of inspection report heights, and average gap between parts of each radial section for experiment 5 with three interacting 15 in. OD cylinders that are 1.625 in. high.

Table 11 Summary of configurations and neutron multiplication factors for experiment 5

Table 12. Measured height of each radial increment, sum of inspection report heights, and average gap between parts of each radial section for experiment 6 with three interacting 15 in. OD cylinders that are 1.75 in. high.

Table 13. Summary of configurations and neutron multiplication factors for experiment 6 .

Table 14. Measured height of each radial increment, sum of inspection report heights, and average gap between parts of each radial section for experiment 7 with three interacting $15 \mathrm{in.}$ OD cylinders that are $1.875 \mathrm{in}$. high

Table 15. Summary of configurations and neutron multiplication factors for experiment 7 ................... 28

Table 16. Assumed average gaps between part of each radial section for the three interacting 2.0 in. high cylinders.

Table 17. Summary of configurations and neutron multiplication factors for experiment 8 .

Table 18. Average dimensions of uranium $\left(93.14 \mathrm{wt} . \%{ }^{235} \mathrm{U}\right)$ metal cylinders and annuli for delayed critical experiments with three $15 \mathrm{in}$. diameter interacting cylinders.

Table 19. Summary of average uranium isotopics of metal cylinders and annuli, for delayed critical experiments with three 15 in. diameter interacting cylinders.

Table 20. Measured impurity content of uranium metal cylinders and annuli for delayed critical experiments with three 15 in. diameter interacting cylinders. 


\begin{abstract}
This report documents very accurately the configuration and the materials for experiments with three unmoderated, unreflected, interacting, coaxial, highly enriched, 15 in. diameter, uranium metal cylinders performed at the Oak Ridge Critical Experiments Facility (ORCEF) in August - October 1963 and described in logbook E-20 associated with experiments in the east cell of ORCEF. The information is sufficiently accurate that it can be used as the basis for preparation of benchmarks for International Criticality Safety Benchmark Program (ICSBEP) at Idaho National Laboratory. The thickness of the cylinders was varied, and the spacing between them was adjusted to achieve a delayed critical configuration. The average enrichment of the uranium metal was 94.14 wt. $\%{ }^{235} \mathrm{U}$. The heights of the 15 in. diameter, equal-height cylinders varied from $11 / 8$ to 2.0 in. All interacting cylinders were assembled coaxially with their flat faces parallel and their combined masses varied between 182 and $325 \mathrm{~kg}$ of highly enriched uranium (HEU) metal. The data from these eight experiments described are judged to be acceptable for use as criticality safety benchmark experiments for the ICSBEP and EURATOM's Nuclear Energy Agency nuclear criticality safety benchmark program, once the uncertainty analysis is completed. Based on previous ICSBEP benchmarks with this enriched uranium metal at ORCEF, the uncertainties in measured $\mathrm{k}_{\text {eff }}$ are expected to be as low as \pm 0.0002 .
\end{abstract}

\title{
1. DESCRIPTION OF MEASUREMENTS
}

\subsection{OVERVIEW OF EXPERIMENT}

A variety of critical experiments were constructed with unreflected and unmoderated highly enriched uranium metal during the 1960s and 1970s at the Oak Ridge Critical Experiments Facility (ORCEF) in support of criticality safety at the Y-12 National Security Complex (Y-12 NSC) [1-7]. Of these hundreds of delayed critical assemblies, eight assemblies of three 15 in. diameter interacting coaxial uranium metal cylinders were assembled to delayed criticality without a moderator or reflector. In one case, the configuration with three $1.5 \mathrm{in}$. high cylinders was repeated with different uranium metal parts. One experiment was repeated with the same uranium metal parts but move to the center of the East cell to evaluate the effect of the proximity of the walls. The height of the three $15 \mathrm{in}$. diameter interacting cylinders varied from 1 1/8 to 2.0 in., with varying separation distances between cylinders. All coaxial interacting cylinders were assembled with their flat faces parallel, and their combined masses varied between 182 and $325 \mathrm{~kg}$ of highly enriched $\left(93.14 \mathrm{wt} . \%{ }^{235} \mathrm{U}\right)$ uranium (HEU) metal. The spacing between cylinders was the variable that was adjusted to achieve delayed criticality. The experiments were performed between August and September 1963. Interaction experiments with 11 in. diameter HEU metal cylinders have been reported to ICSBEP and analyzed in HEU-MET-FAST-051. ${ }^{1}$ Other HEU metal experiments at ORCEF already in the Nuclear Energy Agency benchmark database are HEU-METFAST-059, -061, -071, and -100.

The data from these eight experiments described should be acceptable for use as criticality safety benchmark experiments in the ICSBEP when the uncertainty analysis is performed. Based on previous ICSBEP benchmarks with this enriched uranium metal at ORCEF, the uncertainties in measured $\mathrm{k}_{\text {eff }}$ are expected to be as low as \pm 0.0002 .

\footnotetext{
${ }^{1}$ International Handbook of Evaluated Criticality Safety Benchmark Experiments, NEA/NSC/DOC(95)03/I-IX, Organization for Economic Co-operation and Development - Nuclear Energy Agency (OECD-NEA), September 2006 Edition.
} 


\subsection{DESCRIPTION OF EXPERIMENTAL CONFIGURATION}

These experiments were performed in the $35 \times 35 \times 30 \mathrm{ft}$ high east cell of ORCEF. The assemblies of uranium metal were located approximately $11.7 \mathrm{ft}$ from the $5 \mathrm{ft}$ thick concrete west wall, $12.7 \mathrm{ft}$ from the $2 \mathrm{ft}$ thick concrete north wall, and $9.2 \mathrm{ft}$ above the concrete floor. The purpose of these experiments included evaluating storage and handling limits for the Y-12 NSC and providing data for verification of calculation methods and cross sections for nuclear criticality safety applications. These experiments included single cylinders of various diameters, two interacting cylinders of various diameters, three interacting cylinders, and complex geometry assemblies. All interacting cylinders were assembled coaxially with their flat faces parallel, and the combined masses of the interacting cylinders masses varied between 62 and $325 \mathrm{~kg}$ of HEU metal. The experiments described here are three interacting cylinders with nominal diameters of 15 in. with the nominal height of upper and lower sections varied from 1.125 to $2.00 \mathrm{in}$., with various separation distances between them, unmoderated and unreflected. Note, all dimensions were measured and recorded in inches. When dimensions are rounded to the nearest inch or one-eighth inch, they are nominal dimensions, otherwise they are measured. The eight experiments and the one repeated configuration are summarized in Table 1 . For all configurations the experimental $\mathrm{k}_{\text {eff }}$ was 1.0000. These configurations have the lowest uncertainties and include all the support structure and air in, walls of, and floor of the experimental cell and would be best for checking the accuracy of the ability of calculational methods to predict experimental results. This is because corrections for these effects have uncertainties.

Table 1. Summary of cylinder thicknesses, cylinder masses, and measured separations, and experimental keff for delayed critical experiments with three interacting cylinders of 15 in. diameter uranium metal cylinders.

\begin{tabular}{|c|c|c|c|c|c|c|c|}
\hline Experiment & $\begin{array}{c}\text { Nominal } \\
\text { cylinder } \\
\text { thickness } \\
\text { (in.) }^{\mathbf{a}}\end{array}$ & $\begin{array}{c}\text { Mass of } \\
\text { upper } \\
\text { section } \\
\text { (g) }\end{array}$ & $\begin{array}{c}\text { Mass of } \\
\text { central } \\
\text { section } \\
\text { (g) }\end{array}$ & $\begin{array}{c}\text { Mass } \\
\text { of lower } \\
\text { section } \\
\text { (g) }\end{array}$ & $\begin{array}{c}\text { Total } \\
\text { mass } \\
(\mathbf{g})\end{array}$ & $\begin{array}{c}\text { Measured } \\
\text { separation } \\
\text { (in.) }^{\mathbf{a}}\end{array}$ & $\mathbf{k}_{\text {eff }}$ \\
\hline 1 & 1.125 E-20 page 233 & 60,791 & 60,727 & 60,919 & 182,437 & $0.42410,0.4191$ & 1.0000 \\
\hline 2 & 1.250 E-20 page 229 & 67,853 & 67,558 & 67,717 & 203,128 & $0.8556,0.8818$ & 1.0000 \\
\hline 3 & 1.375 E-20 page 205 & 74,324 & 74,285 & 74,465 & 223,074 & $1.3222,1.3090$ & 1.0000 \\
\hline 4 & 1.500 E-20 page 201 & 81,203 & 81,588 & 81,292 & 244,083 & $1.8106,1.7961$ & 1.0000 \\
\hline 5 & 1.625 E-20 page 161 & 87,757 & 87,897 & 88,069 & 263,723 & $2.30658,2.3222$ & 1.0000 \\
\hline 6 & 1.750 E-20 page 173 & 94,595 & 94,532 & 94,912 & 284,038 & $2.8848,2.8982-$ & 1.0000 \\
\hline 7 & 1.875 E-20 page 180 & 101,430 & 101,330 & 101,613 & 304,373 & $3.5378,3.5198$ & 1.0000 \\
\hline 8 & 2.000 E-20 page 188 & 108,233 & 108,071 & 108,542 & 324,846 & $4.2477,4.24985$ & 1.0000 \\
\hline
\end{tabular}

a The first number is the separation of the upper and middle section, and the second number is the separation of the middle and lower section.

${ }^{\mathrm{b}}$ Assembled with two slightly different separation of the upper and middle cylinder.

\subsection{EXPERIMENT METHODOLOGY}

The three interacting uranium metal cylinders of nominal diameter of 15 in. were assembled to delayed criticality at ORCEF between August and October 1963. The cylinders comprised layers of central discs and surrounding, close-fitting annular ring sections whose dimensions were machined to precise tolerances. The experiments were performed in a deliberate and step-by-step manner, and observed data was recorded. 


\subsubsection{General Assembly Procedure}

The assemblies were constructed on a vertical assembly machine, which primarily consisted of a hydraulic lift (22 in. vertical motion) to support the lower section and a stationary upper half consisting of four vertical posts. The upper support structure shown in Figure 1 was not used in these experiments. Instead two low-mass support structures (shown in Figure 2) were used to support the upper and middle cylinders. The four vertical poles held two low-mass supports consisting of a $30 \mathrm{in.} \mathrm{diameter} \mathrm{clamping}$ ring, which held a 0.010 in. thick stainless-steel diaphragm on which the upper and middle uranium metal cylinders were supported. The bottom uranium metal part of the upper and middle sections was a 15 in. diameter cylindrical disc so that the central 7 in. diameter discs and annular ring section of the upper assembly would not sag with the diaphragm. This ensured that the bottom of the upper section was the same distance above the middle section and that the bottom of the middle section was the same distance above the lower section. The clamping rings were supported by a lightweight aluminum structure mounted on the four vertical poles of the assembly machine, spaced $4 \mathrm{ft}$ apart (see Figure 2). The clamping rings each contained thirty-four $3 / 8$ in. diameter, $1.5 \mathrm{in.} \mathrm{long} \mathrm{stainless-steel} \mathrm{bolts.} \mathrm{The} \mathrm{lower}$ section was supported on a low-mass aluminum support tower mounted on the vertical lift, also shown in Figure 2. The lower support stand supported the uranium metal with 0.125 in. thick aluminum edges, oriented vertically and $120^{\circ}$ apart. Lateral motion of the lower section was restrained by small aluminum pieces bolted to the $120^{\circ}$ vertical members. These are also visible in Figure 2. The low-mass support stand was bolted to the vertical lift as shown in Figure 2. These low-mass support structures were used to minimize the reactivity effects of the support structure. The support structures are described in an Appendix A.

For these experiments the spacing of the upper and middle cylinders was established. Then, the lower section was raised to a separation from the middle cylinder beyond delayed criticality to increase the fission rate to a measurable level. Then the spacing was adjusted by motion of the vertical table until near exactly delayed criticality was achieved (reactor period $>5,000$ seconds). The upper and lower separations were then adjusted so that they were nearly equal. Separation of the upper and lower assemblies was monitored remotely by selsyn readout, which was available in the control room. The selsyn readouts were accurate to \pm 0.0005 in. The separation of the lower and middle cylinders of the assemblies was measured as follows. At several points of the compass, the distances between the top (outer diameter) of the lower uranium cylinder and the bottom of the diaphragm supporting the middle cylinder at the radial location of the outer diameter of the middle cylinder was measured with a micrometer accurate to $0.001 \mathrm{in}$. with the vertical table in the down position. The motion of the table was monitored with a selsyn motor that indicated the height of the lower support table above the down position to $0.001 \mathrm{in}$. This selsyn readout was verified against physical measurements of the height of the lower support table above the down position. There were two selsyn readouts, $180^{\circ}$ apart, which were both used to obtain the separation. The difference between the selsyn readout with the lower support table at the critical position and the selsyn readout with the table down was equal to the distance the vertical support table was raised. The separation between the top of the lower uranium with the vertical table down and the bottom of the stainless-steel diaphragm supporting the middle section was measured. The total separation minus the amount the table as raised is the separation of the two cylinders minus the stainless-steel diaphragm supporting the middle section. The lower diaphragm thickness ( 0.010 in. thick) was added to this difference to obtain the total vertical distance between the middle and lower cylinders. The upper and middle uranium cylinder parts were usually assembled on a 15 in diameter uranium disc that was adjacent to the stainless-steel diaphragm to support the upper uranium at the same height across the whole lower surface, so the measured separations were unambiguous. In some of the early other experiments the $15 \mathrm{in}$. diameter plates were not available, and this resulted in the bottom not being at the same height due to sagging of the diaphragm. This resulted in an uneven top of the upper cylinder. For these eight experiments the separation of the adjacent pairs of cylinders was measured at the outer diameter. 


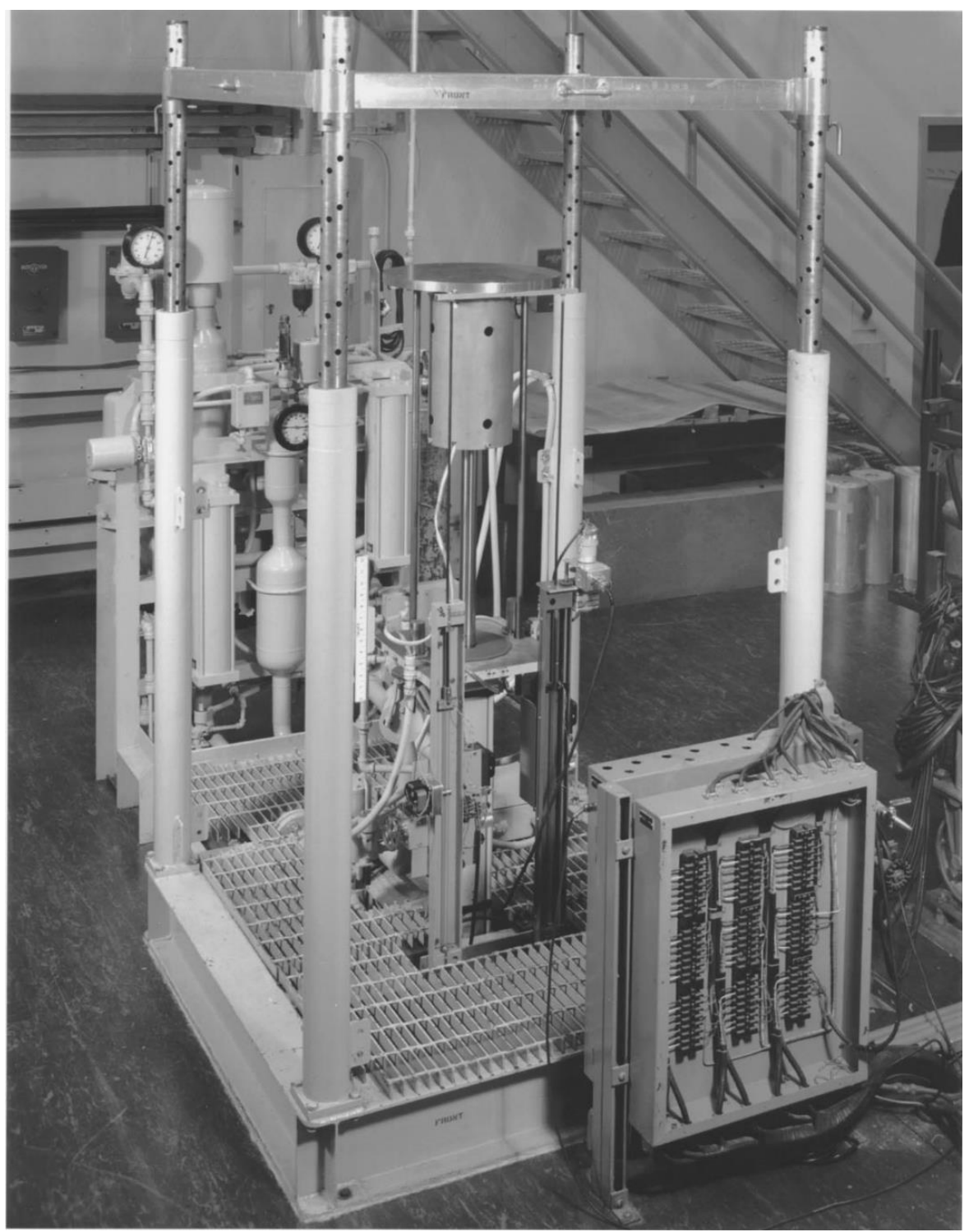

Figure 1. Photograph of the vertical assembly machine with the movable table up. (Upper support structure on the four vertical poles was not used in these measurements. No lower support structures on the movable steel table is in this photograph). ${ }^{2}$

${ }^{2}$ Safety Review of the Oak Ridge Critical Experiments Facility, ORNL/TM-349, Union Carbide Nuclear Corporation, Oak Ridge National Laboratory, Oak Ridge, TN (1962). 


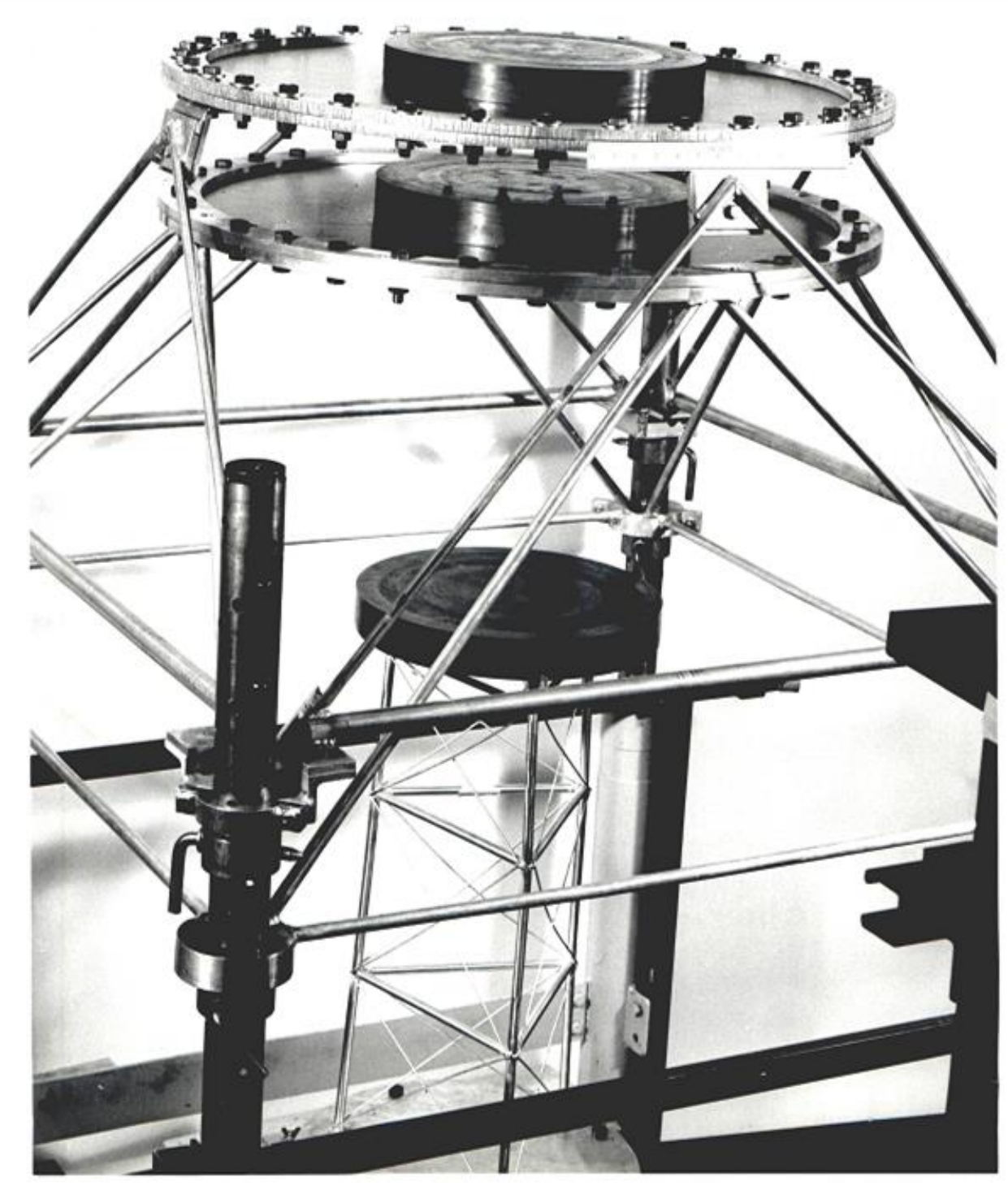

Figure 2. Three interacting 15 in. diameter, 2 in. thick uranium metal cylinders with the lower cylinder on the support stand in the down position.

The assembly heights of the central discs and the surrounding ring sections were measured to \pm 0.0005 in. as follows. Partial safe hand stacking of the appropriate parts on a precision flat surface were used to measure the height of various radial section of the assemblies. For the nominal 15 in. diameter cylinders, each of these assemblies consisted of 7 in. outer diameter (OD) cylinders, 7 in. inner diameter (ID)/9 in. OD annuli, 9 in. ID/11 in. OD annuli, 11 in. ID/13 in. OD annuli, and $13 \mathrm{in.} \mathrm{ID/15} \mathrm{in.} \mathrm{OD} \mathrm{annuli.} \mathrm{In} \mathrm{all}$ experiments the upper and middle cylinders contained a $15 \mathrm{in}$. diameter cylindrical disc on the bottom of each cylinders. For example, for the lower sections, the 7 in. diameter cylinders were stacked on a precision flat surface, and the distance between the upper surface and the precision flat surface was measured. In stacking all parts in the assemblies, the azimuth orientation of the parts was such that the location of the part numbers on the upper surface was always oriented toward the north wall of the experimental cell. This ensured reproducibility when restacking assemblies or parts of assemblies for height measurements. The parts were always positioned with the surface with the scribed part number facing up. Thus, for the height measurements on the precision flat surface, the orientation of the 7 in. 
diameter cylinders was the same as in the assembly. The height of the upper and lower sections of the 7 in. diameter cylinders was normally measured at azimuth locations N, E, S, W, SW, and NE, and the values were averaged. To obtain the average void in these stacks of parts, the sum of the actual measured heights of all the parts was subtracted from the measured stack height. This process was repeated for all applicable annuli, and each annulus stack was measured separately. This process was separately performed for the lower section and the upper and middle section. For the upper and middle sections that were stacked on a 15 in. diameter disc, the bottom cylindrical plate was on the flat surface, and the appropriate radial sections of the assembly were stacked on the uranium plate for the height measurements for each radial section. This procedure allowed the safe measurements of the stacked height of each concentric annulus and the central cylinder. The average measured heights for the cylinder and annular sets and the average for each assembly are given in the description of each measurement.

\subsubsection{Lateral Alignment of the Lower Section with the Middle Section}

For this alignment, the procedure is the same as with two interacting cylinders described in HEU-METFAST-051. This was performed without the top diaphragm mounted on the vertical assembly machine.

\subsubsection{Middle Section}

For assembly of the middle section, uranium metal was added to the lower diaphragm. Uranium was located with a ruler the appropriate distance from the inside of the aluminum ring, which holds the stainless diaphragm. A plate of uranium metal (15 in.-OD) was placed on the diaphragm, and additional material was stacked on the uranium metal plate. Layers of uranium metal for a 15 in. diameter cylinder typically consisted of a $7 \mathrm{in}$. diameter cylinder, $7 \mathrm{in.} \mathrm{ID/9} \mathrm{in.} \mathrm{OD} \mathrm{annulus,} 9 \mathrm{in.} \mathrm{ID/11} \mathrm{in.} \mathrm{OD} \mathrm{annulus,}$ 11 in. ID/13 in. OD annulus, and a $13 \mathrm{in.} \mathrm{ID/15} \mathrm{in.} \mathrm{OD} \mathrm{annulus.} \mathrm{The} \mathrm{rest} \mathrm{of} \mathrm{the} \mathrm{material} \mathrm{was} \mathrm{then} \mathrm{added}$ to the middle cylinder. The location of the material was continuously adjusted with a precise high-quality level with the level in one direction and then rotated $90^{\circ}$ on the parts. If the assembly was not exactly centered in the diaphragm, it would not be precisely level because the diaphragm would sag as it was loaded. The locations of various layers of material were adjusted so that the outside radii were the same. Two precisely machined steel blocks ( $\pm 0.0001 \mathrm{in}$.) were used to squeeze the material at the outer radial surface until it was aligned radially. An edge of the machined block was held at one outside radial location, and material was adjusted until no light was visible between the machined block and the uranium metal. This process was repeated $90^{\circ}$ from the position of the original adjustment, rechecked again at the original position, and small adjustments were made if necessary. This process continued until the outside radii of the parts were precisely aligned and the upper-section assembly was complete. The alignment of outer radii of the middle section was less than \pm 0.001 in. Of course, if two positions $90^{\circ}$ apart are adjusted, the positions at $180^{\circ}$ and $270^{\circ}$ can be off only by the difference in the diameters of the outside parts.

\subsubsection{Lower Section}

For the lower section, the same procedure was used except that leveling of the parts was accomplished by shimming with aluminum foil. Various thicknesses of aluminum foil were available. The foil was placed between the three $120^{\circ}$ upper edges of the support stand and the lowest parts so that the upper surface of the lower cylinder was flat. Uncertainty in radial alignment of parts on the middle and lower section is \pm 0.002 in.

\subsubsection{Lateral Alignment of the Middle Section with the Lower Section}

There were two identical fixtures (see Figure 3) used for lateral alignment between the middle section and the lower section. They were U-shaped and were machined out of $0.375 \mathrm{in}$. thick aluminum. The end 
pieces were carefully machined at the Y-12 shops to be perpendicular to the long direction of the fixture and coplanar with each other. When leveled properly, the front face of the $4 \times 4 \times 1 / 2$ in. end pieces were vertical and in the same plane to within \pm 0.001 in. This fixture was carefully machined and handled delicately when not in use so as not to damage it. In use, the lower side of the upper leg rested on the top surface of the clamping ring for the diaphragm. The fixture was perpendicular to the outer radial surface of the cylinder. The fixture was moved inward until it touched the uranium of the middle section. The leveling screws were adjusted until the fixture was level.

The second fixture was placed $90^{\circ}$ apart from the first in a similar manner. Both fixtures were moved back slightly, and the lower section was raised until part of the lower cylinder was as high as the lower end piece of the fixture. Then, both fixtures were nearly adjusted properly. The fixtures were moved in until they touched uranium (either on the top or the lower section). When lack of contact was observed at either of the front faces of the fixture, the lower section was lowered to the full-out position, and the position of the uranium on the lower support stand was adjusted. The lower lift table was raised, and the alignment was checked.

The process was repeated several times as necessary. The final 0.005 in. adjustments were usually made by moving the top section. This was a long and tedious procedure, which took up to 12 hours or more as needed; however, it was always performed. This resulted in the middle and lower sections being aligned within \pm 0.005 in. For close spacing between cylinders, alignment was done with partial loading with these fixtures.

\subsubsection{Lateral Alignment of the Middle Section with the Upper Section}

After the alignment of the middle and lower section, the upper diaphragm was installed on the four vertical poles of the vertical assembly machine and was spaced so that the upper diaphragm was at the estimated distance from the lower diaphragm. Then with the vertical lift in the down position, a $15 \mathrm{in}$. OD uranium metal plate was added to the top diaphragm. After approximating the location, the procedure for assembling the middle section was repeated for the upper section, and the upper section was located laterally with respect to the middle section in a similar fashion to the procedure used for lateral alignment of the middle and lower section.

\section{Summary of cylinder alignment}

- Uncertainty in radial alignment of parts on the upper, middle, and lower section is \pm 0.002 in. for each section

\section{Lateral alignment accuracy summary for three interacting cylinders}

- For the middle and lower assembly, the alignment uncertainty is \pm 0.005 in. For the middle and upper assembly, the alignment uncertainty is \pm 0.005 in. 


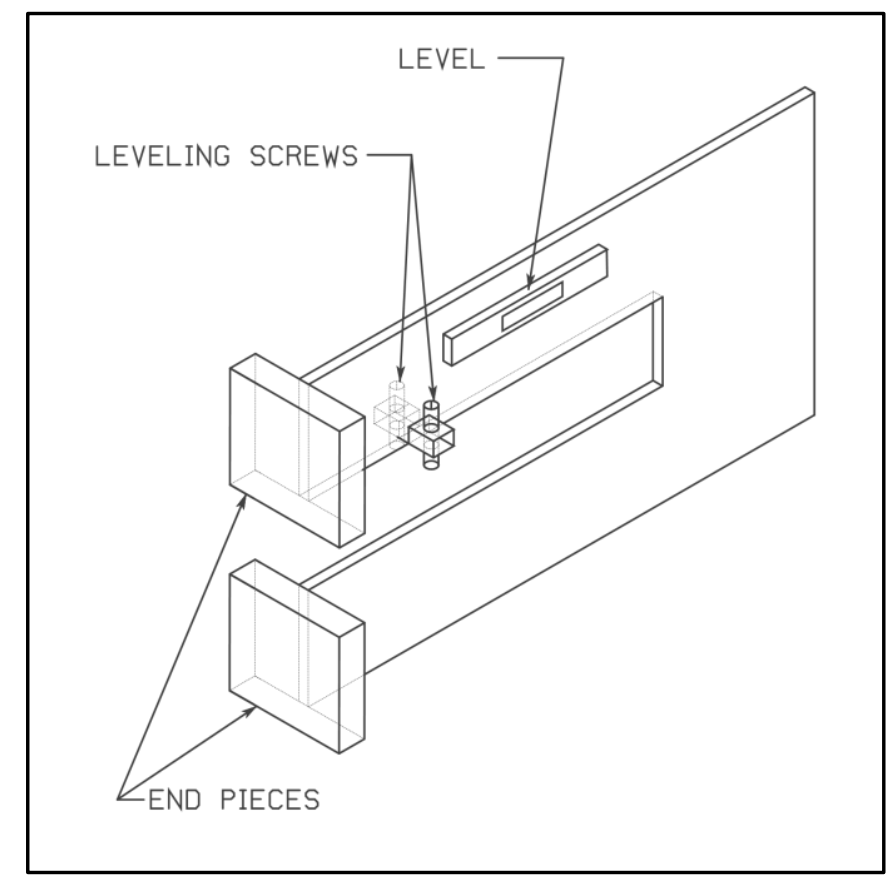

Figure. 3. Sketch of the fixture for lateral alignment of uranium metal cylinders.

\subsubsection{Upward Motion Limitation}

To prevent the vertical table supporting the lower uranium cylinder from getting too close to the middle cylinder, there were two adjustable flanges on $1 \mathrm{in}$. diameter threaded rods attached to the bottom of the 1 in. thick plate of the vertical table. These threaded steel rods were $180^{\circ}$ apart and penetrated through the thick plate that the movable table rested on when down. As the vertical table moved upward, its motion was limited when the flanges came in contact with the bottom of the fixed steel plate. The location of the flanges with respect to the bottom of the fixed table was measured using vertical distance transmitters that measured the last 0.050-0.001 in. The transmitters were used to measure small displacements of the lower uranium cylinder from the upper. These had to be adjusted in steps appropriately to achieve the position of the lower movable table for criticality. Once adjusted they were used to measure small displacements of the lower table from the critical position. In some experiments they were not adjusted properly and were not providing position measurements for the last $0.05 \mathrm{in}$.

\subsubsection{Position Measurement}

The upward location of the vertical table was measured by two mechanical selsyns that read out to $0.001 \mathrm{in}$. When the vertical table was in the down position, they were adjusted to read 00.000. In many cases, in down position they read slightly different from zero. In these cases, the difference had to be added or subtracted from the distance from upper surface of the lower uranium to the under surface of the diaphragm supporting the upper uranium cylinder which was measured at several locations to $0.001 \mathrm{in}$. with an inside micrometer. These measurements were performed at many angular locations corresponding to the outer lower surface of the uranium cylinders where the uranium was in close contact with the diaphragm. The thickness of the diaphragm was added to the micrometer reading to get the total distance between the uranium cylinders with the vertical table in the down position. This distance with the distance the table was moved upward was used to get the separation of the upper and lower uranium cylinders. 


\section{DETAILS OF EXPERIMENTS}

These eight experiments are summarized in Table 1 on page 2 of this report. The descriptions of the assemblies are extracted from the referenced logbook pages.

\subsection{EXPERIMENT 1}

On October 2, 1963, a symmetric assembly of three 15 in. diameter, interacting coaxial uranium metal cylinders with a nominal height of 1.125 in. was measured at delayed criticality with a separation distance of $0.4241 \mathrm{in}$. between the upper and middle cylinder and a separation of $0.4191 \mathrm{in}$. between the middle and the lower cylinder. This assembly is depicted in Figure 4, which shows the assembled configuration with the support structure. This configuration would be the best for comparing calculated $\mathrm{k}_{\text {eff }}$ with measurements because there are no corrections to the system with their associated uncertainties. This comparison calculation should include the support structure, the air in the room, and the walls, floor, and ceiling of the experimental cell. The lower, middle, and upper cylinder of the experiment had masses of $60,919,60,727$, and $60,781 \mathrm{~g}$, respectively, for a total uranium metal mass of $182,427 \mathrm{~g}$. The presence of the support structure consisting of the diaphragms, diaphragm support rings, and the lower support stand was evaluated. In some cases, the reactivity was measured, and in others only the change in separation was measured. Without these supports, the separation of the middle and lower cylinder would have been 0.0214 in. closer (i.e., 0.3977 in.). The reactivity change associated with a change in separation of the middle and lower cylinder was measured at 1.27 cents per thousandth of an inch (cents/mil). Without the air in the cell and the cell structure, the separation would have been lower yet. The measured height of each radial increment of the upper and lower cylinder, the sum of the measured heights of the individual parts, and the difference from which the average air gap between parts that composed the central 7 in. diameter section and the various annuli are given in Table 2 . These gaps should be included in the detailed model when comparing calculations with measurements.

Table 2. Measured height of each radial increment, sum of inspection report heights, and average gap between parts of each radial section for experiment 1 with three interacting 15 in. OD cylinders that are 1.125 in. high.

\begin{tabular}{|c|c|c|c|c|c|c|}
\hline \multirow{2}{*}{ Cylinder } & \multirow{2}{*}{ Quantity } & \multicolumn{5}{|c|}{$\begin{array}{c}\text { Measured heights, sum of part thicknesses, and gaps (mils) for } \\
\text { radial thicknesses of }\end{array}$} \\
\hline & & 7 in. $\mathrm{OD}$ & $\begin{array}{l}7 \text { in. ID- } \\
9 \text { in. OD }\end{array}$ & $\begin{array}{l}9 \text { in. ID- } \\
11 \text { in. OD }\end{array}$ & $\begin{array}{l}11 \text { in. ID- } \\
13 \text { in. } O D\end{array}$ & $\begin{array}{l}13 \text { in. ID- } \\
15 \text { in. OD }\end{array}$ \\
\hline \multirow{4}{*}{ Upper } & Measured height (in.) & 1.1250 & 1.1245 & 1.1230 & 1.1272 & 1.1266 \\
\hline & Sum of part thicknesses (in.) & 1.12195 & 1.12045 & 1.11825 & 1.1241 & 1.12475 \\
\hline & Number of gaps & 1 & 1 & 1 & 2 & 2 \\
\hline & Average gap (mils) & 3.1 & 4.1 & 4.7 & 1.55 & 0.9 \\
\hline \multirow{4}{*}{ Middle } & Measured height (in.) & 1.1263 & 1.1268 & 1.1263 & 1.1274 & 1.1238 \\
\hline & Sum of part thicknesses (in.) & 1.11895 & 1.11985 & 1.11635 & 1.12585 & 1.12085 \\
\hline & Number of gaps & 3 & 3 & 3 & 3 & 3 \\
\hline & Average gap (mils) & 2.5 & 2.3 & 3.3 & 0.5 & 1.0 \\
\hline \multirow{4}{*}{ Lower } & Measured height (in.) & 1.1265 & 1.1263 & 1.1280 & 1.1268 & 1.1258 \\
\hline & Sum of part thicknesses (in.) & 1.1277 & 1.12388 & 1.12825 & 1.12505 & 1.1230 \\
\hline & Number of gaps & 1 & 1 & 1 & 1 & 1 \\
\hline & Average gap (mils) & 0.0 & 2.75 & 0.0 & 1.8 & 2.8 \\
\hline
\end{tabular}



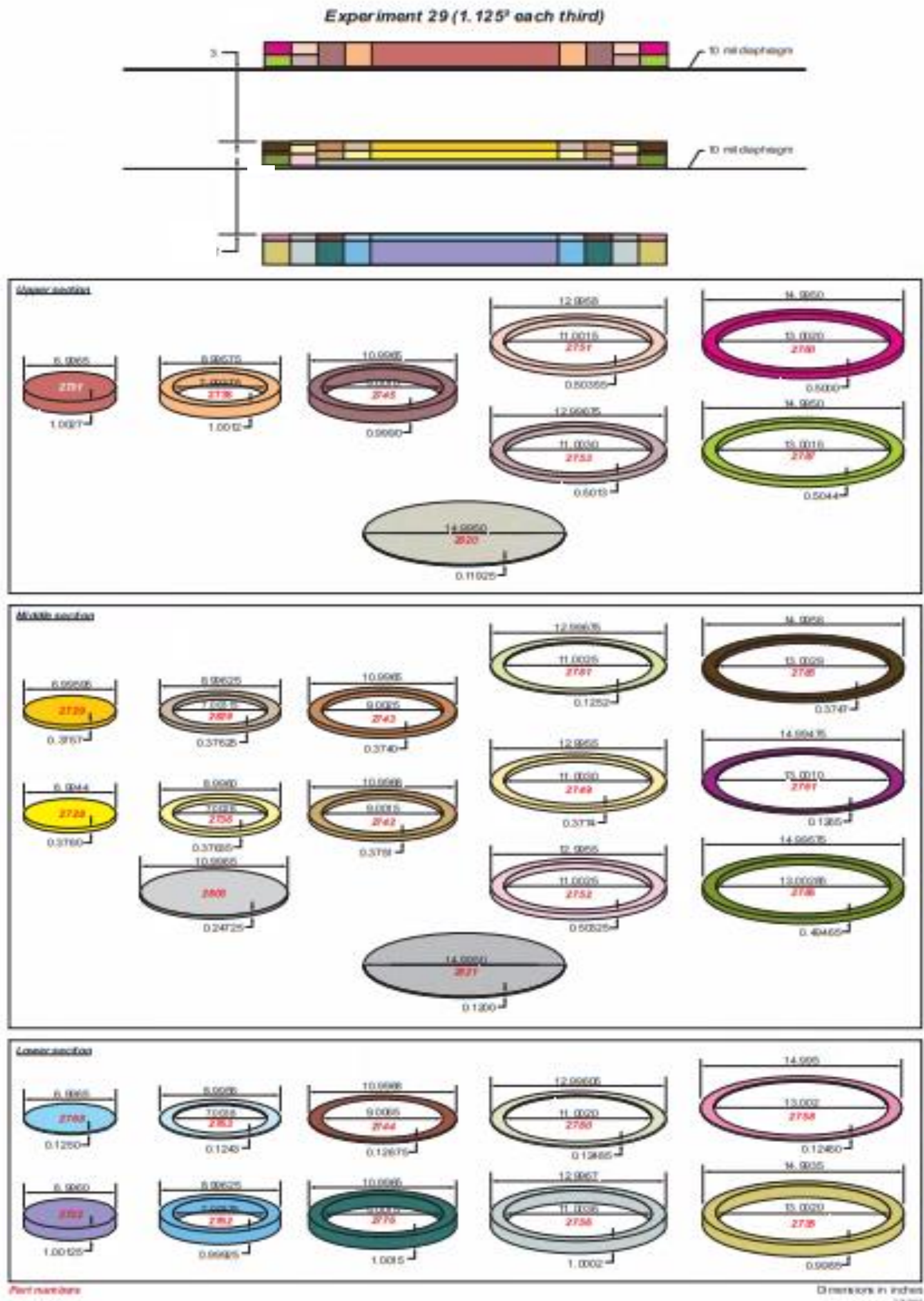

Figure 4. Experiment 1-Configuration of delayed critical unreflected, unmoderated uranium (93.14 wt.\%

${ }^{235} \mathrm{U}$ ) metal $15 \mathrm{in}$. diameter three interacting cylinders with a nominal height of $1.125 \mathrm{in}$. (configuration drawing provided by John Bess of Idaho National Laboratory) 
The effects of room return should be calculated by Monte Carlo simulations assuming the wall and floor were $2 \mathrm{ft}$. thick. The concrete can be assumed to be Oak Ridge concrete, which used crushed limestone instead of sand in the aggregate. For this calculation $2 \mathrm{ft}$. is adequate because neutrons penetrating more that have little chance of getting back to the assembly. In summary, the configurations for experiment 1 and the $\mathrm{k}_{\text {eff }}$ values are given in Table 3 .

Table 3. Summary of configurations and neutron multiplication factors for experiment 1.

\begin{tabular}{|l|c|c|}
\hline \multicolumn{1}{|c|}{ Configuration } & $\begin{array}{c}\text { Spacing } \\
\text { (in.) }\end{array}$ & $\begin{array}{c}\text { Neutron } \\
\text { multiplication } \\
\text { factor } \\
\left(\mathbf{k}_{\text {eff }}\right)\end{array}$ \\
\hline $\begin{array}{l}\text { With support structure, no correction for } \\
\text { room return }\end{array}$ & $0.4241,0.4191$ & 1.00000 \\
\hline $\begin{array}{l}\text { Without support structure, no correction } \\
\text { for room return }\end{array}$ & $0.4241,0.3977$ & 1.00000 \\
\hline
\end{tabular}

${ }^{a}$ First number is the top-to-middle separation and the second is the middle-to-bottom separation.

In addition, the prompt neutron decay constant at delayed criticality (starting on October 2, 1963) was measured by the Rossi- $\alpha$ method but is not reported here.

\subsection{EXPERIMENT 2}

On October 4, 1963, a symmetric assembly of three 15 in. diameter, interacting coaxial uranium metal cylinders with a nominal height of 1.25 in. was measured at delayed criticality with a separation distance of $0.8556 \mathrm{in}$. between the upper and middle cylinder and a separation of $0.8818 \mathrm{in}$. between the middle and the lower cylinder. The makeup of the assembly is depicted in Figure 5, which shows the assembled configuration with the diaphragms for the upper- and middle-cylinders support. This configuration would be the best for comparing calculated $\mathrm{k}_{\text {eff }}$ with measurements because there are no corrections to the system for their associated uncertainties. This comparison calculation should include the support structure, the air in the room, and the walls, floor, and ceiling of the experimental cell. The lower, middle, and upper cylinder of the experiment had masses of $67,717,67,558$, and $67,853 \mathrm{~g}$, respectively, for a total uranium metal mass of 203,128 g. The presence of the support structure consisting of the diaphragms, diaphragm support rings, and the lower support stand was evaluated. In some cases, the reactivity was measured, and in others only the change in separation was measured. Without these supports, the separation of the middle and lower cylinder would have been 0.0296 in. closer (i.e., 0.8522 in.). The reactivity change associated with a change in separation of the middle and lower cylinder was measured at 1.11 cents $/ \mathrm{mil}$. Without the air in the cell and the cell structure, the separation would have been lower yet. The measured height of the various sections of the upper and lower cylinder, the sum of the measured heights of the individual parts, and the difference from which the average air gap between parts that composed the central 7 in. diameter section and the various annuli are given in Table 4. These gaps should be included in the detailed model when comparing calculations with measurements. 

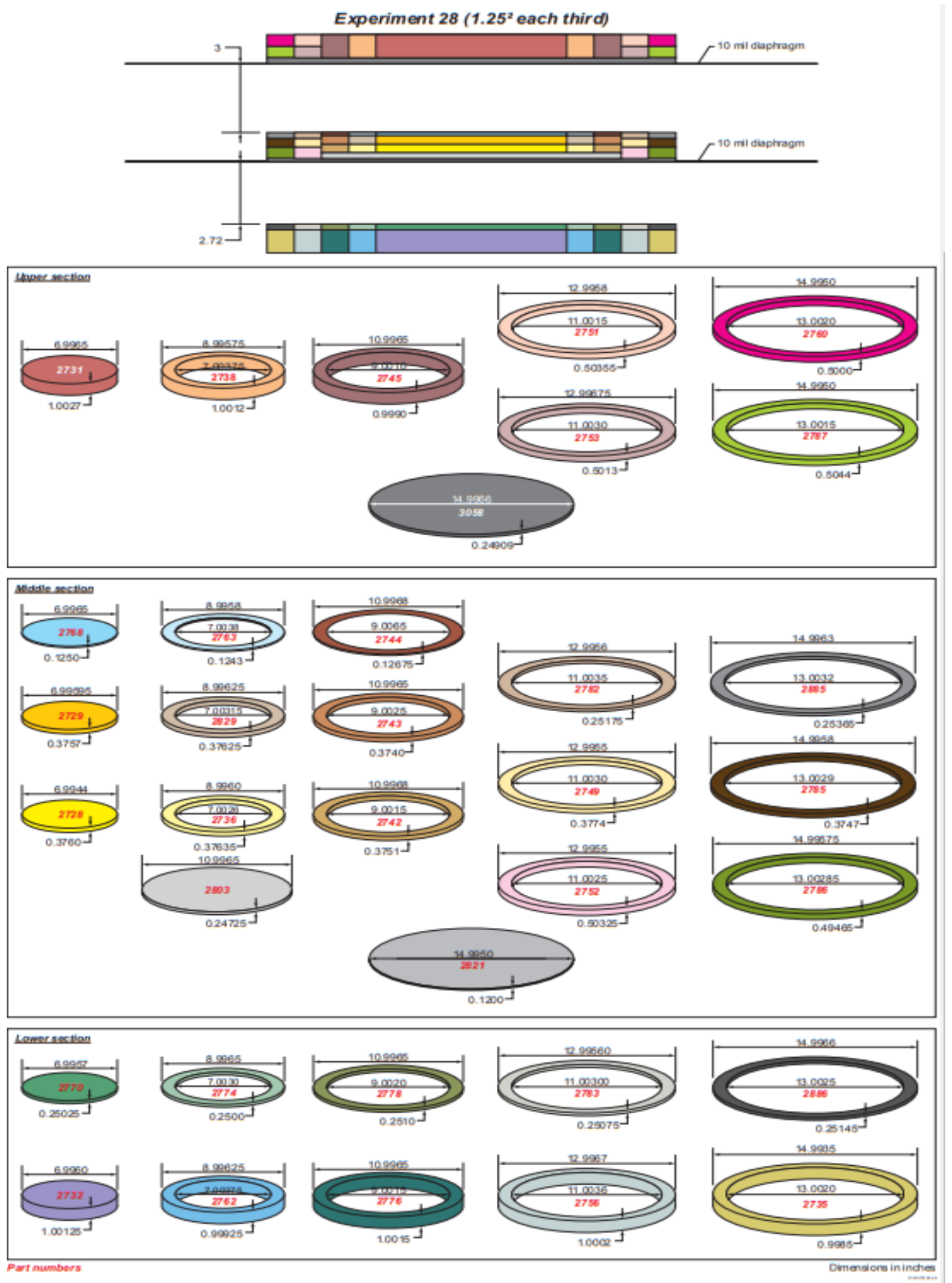

Figure 5. Experiment 2-Configuration of delayed critical unreflected, unmoderated uranium $(93.14 \mathrm{wt} . \%$ ${ }^{235} \mathrm{U}$ ) metal $15 \mathrm{in}$. diameter three interacting cylinders with nominal height of $1.25 \mathrm{in}$. (configuration drawing provided by John Bess of Idaho National laboratory) 
Table 4. Measured height of each radial increment, sum of inspection report heights and average gap between parts of each radial section for experiment 2 with three interacting 15 in. OD cylinders that are $1.25 \mathrm{in}$. high.

\begin{tabular}{|c|c|c|c|c|c|c|}
\hline \multirow{2}{*}{ Cylinder } & \multirow{2}{*}{ Quantity } & \multicolumn{5}{|c|}{$\begin{array}{l}\text { Measured heights, sum of part thicknesses, and gaps (mils) for } \\
\text { radial thicknesses of }\end{array}$} \\
\hline & & 7 in. OD & $\begin{array}{l}7 \text { in. ID- } \\
9 \text { in. OD }\end{array}$ & $\begin{array}{l}9 \text { in. ID- } \\
11 \text { in. OD }\end{array}$ & $\begin{array}{l}11 \text { in. ID- } \\
13 \text { in. OD }\end{array}$ & $\begin{array}{l}13 \text { in. ID- } \\
15 \text { in. OD }\end{array}$ \\
\hline \multirow{4}{*}{ Upper } & Measured height (in.) & 1.2580 & 1.2562 & 1.2547 & 1.2596 & 1.2596 \\
\hline & Sum of part thicknesses (in.) & 1.25179 & 1.25028 & 1.24809 & 1.25394 & 1.25459 \\
\hline & Number of gaps & 1 & 1 & 1 & 2 & 2 \\
\hline & Average gap (mils) & 6.2 & 5.9 & 6.6 & 2.8 & 2.5 \\
\hline \multirow{4}{*}{ Middle } & Measured height (in.) & 1.2532 & 1.2533 & 1.2553 & 1.2577 & 12564 \\
\hline & Sum of part thicknesses (in.) & 1.24395 & 1.244151 & 1.2431 & 1.2524 & 1.2480 \\
\hline & Number of gaps & 4 & 4 & 4 & 3 & 3 \\
\hline & Average gap (mils) & 2.3 & 2.3 & 3.1 & 1.8 & 2.8 \\
\hline \multirow{4}{*}{ Lower } & Measured height (in.) & 1.2529 & 1.2524 & 1.2543 & 1.2527 & 1.2528 \\
\hline & Sum of part thicknesses (in.) & 1.2515 & 1.24925 & 1.2414 & 1.25095 & 1.24995 \\
\hline & Number of gaps & 1 & 1 & 1 & 1 & 1 \\
\hline & Average gap (mils) & 1.4 & 3.2 & 2.5 & 1.8 & 2.9 \\
\hline
\end{tabular}

The effects of room return should be calculated by Monte Carlo simulations assuming the wall and floor were $2 \mathrm{ft}$ thick. The concrete can be assumed to be Oak Ridge concrete, which used crushed limestone instead of sand in the aggregate. For this calculation $2 \mathrm{ft}$. is adequate because neutrons penetrating more that have little chance of getting back to the assembly. In summary the configurations for experiment 2 and the $\mathrm{k}_{\text {eff }}$ values are given in Table 5 .

Table 5. Summary of configurations and neutron multiplication factors for experiment 2.

\begin{tabular}{|l|c|c|}
\hline \multicolumn{1}{|c|}{ Configuration } & \multicolumn{1}{|c|}{$\begin{array}{c}\text { Spacing } \\
\text { (in.) }\end{array}$} & $\begin{array}{c}\text { Neutron } \\
\text { multiplication } \\
\text { factor }^{\mathbf{a}} \\
\left(\mathbf{k}_{\text {eff }}\right)\end{array}$ \\
\hline $\begin{array}{l}\text { With support structure, no correction for } \\
\text { room return }\end{array}$ & $0.8556,0.8818$ & 1.00000 \\
\hline $\begin{array}{l}\text { Without support structure, no correction } \\
\text { for room return }\end{array}$ & $0.8556,0.8522$ & 1.00000 \\
\hline
\end{tabular}

aFirst number is the top-to-middle separation and the second is the middle-to-bottom separation.

In addition, the prompt neutron decay constant at delayed criticality (May 21, 1963) was measured using the Rossi- $\alpha$ method (October 4, 1963) but is not reported here. 


\subsection{EXPERIMENT 3}

On September 26, 1963, a symmetric assembly of three 15 in. diameter, interacting coaxial uranium metal cylinders with a nominal height of 1.375 in. was measured at delayed criticality with a separation distance of $1.3322 \mathrm{in}$. between the upper and middle cylinder and a separation of $1.3185 \mathrm{in}$. between the middle and the lower cylinder. The makeup of the assembly is depicted in Figure 6, which shows the assembled configuration with the diaphragms for the upper and lower cylinder supports. This configuration would be the best for comparing calculated $\mathrm{k}_{\text {eff }}$ with measurements because there are no corrections to the system for their associated uncertainties. This comparison calculation should include the support structure, the air in the room, and the walls, floor, and ceiling of the experimental cell. The lower, middle, and upper cylinder of the experiment had masses of 74,324,74,285, and 74,465 g, respectively, for a total uranium metal mass of $223,074 \mathrm{~g}$. The presence of the support structure consisting of the diaphragms, diaphragm support rings, and the lower support stand was evaluated. In some cases, the reactivity was measured, and in others only the change in separation was measured. Without these supports, the separation of the middle and lower cylinder would have been 0.0352 in. closer (i.e., 1.2833 in.). The reactivity change associated with a change in separation of the middle and lower cylinder was measured at $0.97 \mathrm{cents} / \mathrm{mil}$. Without the air in the cell and the cell structure, the separation would have been lower yet. The measured height of the various sections of the upper and lower cylinder, the sum of the measured heights of the individual parts, and the difference from which the average air gap between parts that composed the central 7 in. diameter section and the various annuli are given in Table 6. These gaps should be included in the detailed model when comparing calculations with measurements. 

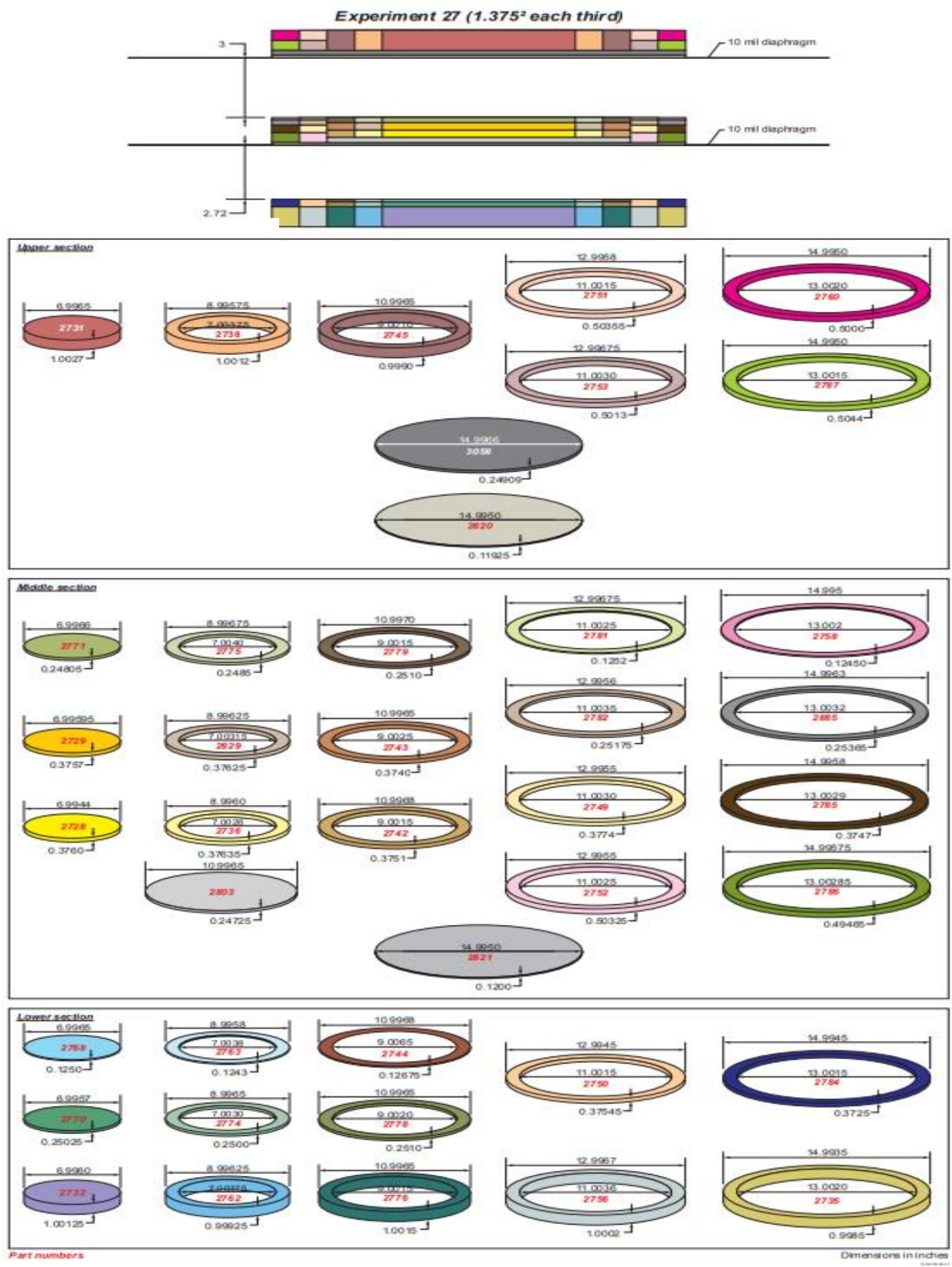

Figure 6. Experiment 3 - Configuration of delayed critical unreflected, unmoderated uranium (93.14 wt. ${ }^{235} \mathrm{U}$ ) metal 15 in. diameter three interacting cylinders with a nominal height of 1.375 in. (Configuration drawing provided by John Bess of Idaho National laboratory) 
The effects of room return should be calculated by Monte Carlo simulations assuming the wall and floor were $2 \mathrm{ft}$. thick. The concrete can be assumed to be Oak Ridge concrete, which used crushed limestone instead of sand in the aggregate. For this calculation $2 \mathrm{ft}$. is adequate because neutrons penetrating more that have little chance of getting back to the assembly. In summary the configurations for experiment 3 and the $\mathrm{k}_{\text {eff }}$ values are given in Table 7.

Table 7. Summary of configurations and neutron multiplication factors for experiment 3.

\begin{tabular}{|l|c|c|}
\hline \multicolumn{1}{|c|}{ Configuration } & $\begin{array}{c}\text { Spacinga } \\
\text { (in.) }\end{array}$ & $\begin{array}{c}\text { Neutron } \\
\text { multiplication } \\
\text { factor } \\
\left(\mathbf{k}_{\text {eff }}\right)\end{array}$ \\
\hline $\begin{array}{l}\text { With support structure, no correction for } \\
\text { room return }\end{array}$ & $1.3322,1.3185$ & 1.00000 \\
\hline $\begin{array}{l}\text { Without support structure, no correction } \\
\text { for room return }\end{array}$ & $1.3322,1.2833$ & 1.00000 \\
\hline
\end{tabular}

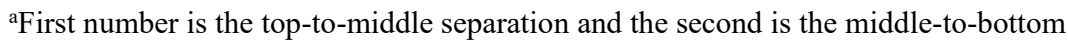
separation.

In addition, the prompt neutron decay constant at delayed criticality was measured using the Rossi- $\alpha$ method (September 26, 1963) but is not reported here.

\subsection{EXPERIMENT 4}

On August 27, 1963, a symmetric assembly of three 15 in. diameter, interacting coaxial uranium metal cylinders with a nominal height of $1.5 \mathrm{in}$. was measured at delayed criticality with a separation distance of $1.8106 \mathrm{in}$. between the upper and middle cylinder and a separation of $1.7851 \mathrm{in}$. between the middle and the lower cylinder. The makeup of the assembly is depicted in Figure 7, which shows the assembled configuration with the diaphragms for the upper- and lower-cylinder supports. This configuration would be the best for comparing calculated $\mathrm{k}_{\text {eff }}$ with measurements because there are no corrections to the system for their associated uncertainties. This comparison calculation should include the support structure, the air in the room, and the walls, floor, and ceiling of the experimental cell. The lower, middle, and upper cylinder of the experiment had masses of $81,203,81,588$, and 81,292 $\mathrm{g}$, respectively, for a total uranium metal mass of $244,083 \mathrm{~g}$. The presence of the support structure consisting of the diaphragms, diaphragm support rings, and the lower support stand was evaluated. In some cases, the reactivity was measured, and in others only the change in separation was measured. Without these supports, the separation of the middle and lower cylinder would have been 0.0414 in. closer (i.e., $1.7437 \mathrm{in}$.). The reactivity change associated with a change in separation of the middle and lower cylinder was measured at 0.73 cents $/ \mathrm{mil}$. Without the air in the cell and the cell structure, the separation would have been lower yet. The measured height of the various sections of the upper and lower cylinder, the sum of the measured heights of the individual parts, and the difference from which the average air gap between parts that composed the central 7 in. diameter section and the various annuli are given in Table 8. These gaps should be included in the detailed model when comparing calculations with measurements. 
Table 8. Measured height of each radial increment, sum of inspection report heights, and average gap between parts of each radial section for experiment 4 with three interacting $15 \mathrm{in}$. OD cylinders that are $1.5 \mathrm{in.} \mathrm{high.}$

\begin{tabular}{|c|c|c|c|c|c|c|}
\hline \multirow{2}{*}{ Cylinder } & \multirow{2}{*}{ Quantity } & \multicolumn{5}{|c|}{$\begin{array}{c}\text { Measured heights, sum of part thicknesses, and gaps(mils) for } \\
\text { radial thicknesses of }\end{array}$} \\
\hline & & 7 in. OD & $\begin{array}{l}7 \text { in. ID- } \\
9 \text { in. OD }\end{array}$ & $\begin{array}{l}9 \text { in. ID- } \\
11 \text { in. OD }\end{array}$ & $\begin{array}{l}11 \text { in. ID- } \\
13 \text { in. OD }\end{array}$ & $\begin{array}{l}13 \text { in. ID- } \\
15 \text { in. OD }\end{array}$ \\
\hline \multirow{4}{*}{ Upper } & Measured height (in.) & 1.5065 & 1.5046 & 1.5075 & 1.5043 & 1.5081 \\
\hline & Sum of part thicknesses (in.) & 1.49725 & 1.49521 & 1.49599 & 1.49584 & 1.49779 \\
\hline & Number of gaps & 2 & 2 & 2 & 3 & 2 \\
\hline & Average gap (mils) & 4.6 & 4.7 & 5.8 & 2.8 & 5.2 \\
\hline \multirow{4}{*}{ Middle } & Measured height (in.) & 1.4977 & 1.5000 & 1.5023 & 1.5068 & 1.5083 \\
\hline & Sum of Part thicknesses (in.) & 1.49604 & 1.49384 & 1.49409 & 1.49475 & 1.49187 \\
\hline & Number of gaps & 5 & 5 & 5 & 5 & 5 \\
\hline & Average gap (mils) & 1.1 & 1.2 & 1.6 & 2.4 & 3.3 \\
\hline \multirow{4}{*}{ Lower } & Measured height (in.) & 1.5026 & 1.500 & 1.4999 & 1.505 & 1.5027 \\
\hline & Sum of part thicknesses (in.) & 1.5026 & 1.500 & 1.49999 & 1.50575 & 1.4985 \\
\hline & Number of gaps & 0 & 0 & 0 & 1 & 1 \\
\hline & Average gap (mils) & 0 & 0 & 0 & 1.3 & 4.2 \\
\hline
\end{tabular}



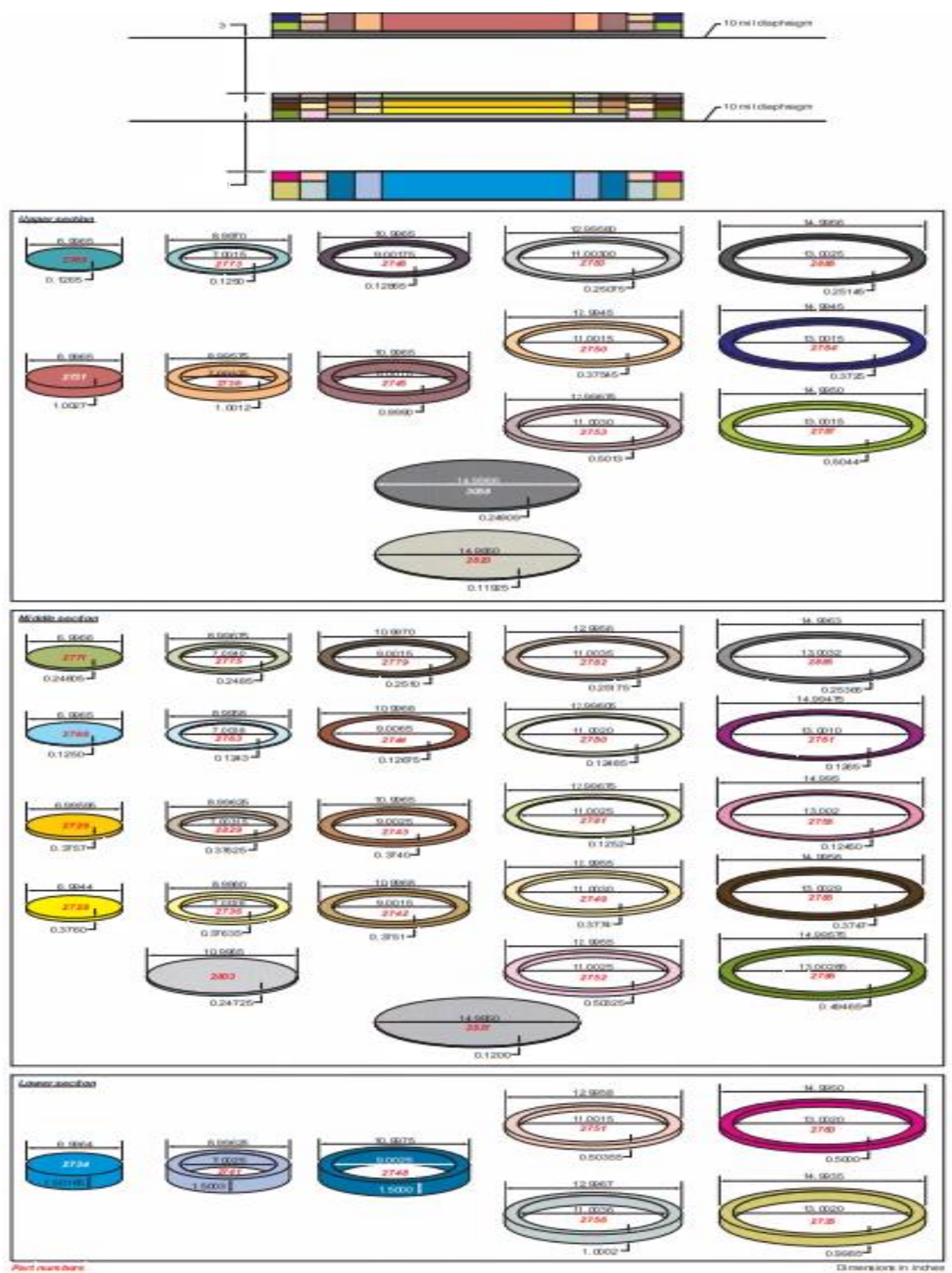

Figure 7. Experiment 4-Configuration of delayed critical unreflected, unmoderated uranium (93.14 wt.\% ${ }^{235} \mathrm{U}$ ) metal $15 \mathrm{in}$. diameter three interacting cylinders with nominal height of $1.5 \mathrm{in}$. (configuration drawing provided by John Bess of Idaho National laboratory) 
The effects of room return should be calculated by Monte Carlo simulations assuming the wall and floor were $2 \mathrm{ft}$ thick. The concrete can be assumed to be Oak Ridge concrete, which used crushed limestone instead of sand in the aggregate. For this calculation $2 \mathrm{ft}$. is adequate because neutrons penetrating more that have little chance of getting back to the assembly. In summary the configurations for experiment 4 and the $\mathrm{k}_{\text {eff }}$ values are given in Table 9.

Table 9. Summary of configurations and neutron multiplication factors for experiment 4.

\begin{tabular}{|l|c|c|}
\hline \multicolumn{1}{|c|}{ Configuration } & $\begin{array}{c}\text { Spacinga } \\
\text { (in.) }\end{array}$ & $\begin{array}{c}\text { Neutron } \\
\text { multiplication } \\
\text { factor } \\
\left(\mathbf{k}_{\text {eff }}\right)\end{array}$ \\
\hline $\begin{array}{l}\text { With support structure, no correction for } \\
\text { room return }\end{array}$ & $1.8106,1.7851$ & 1.00000 \\
\hline $\begin{array}{l}\text { Without support structure, no correction } \\
\text { for room return }\end{array}$ & $1.8106,1.7437$ & 1.00000 \\
\hline
\end{tabular}

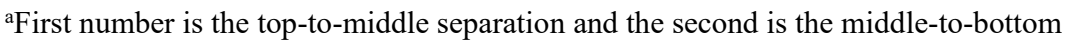
separation.

In addition, the prompt neutron decay constant at delayed criticality was measured using the Rossi- $\alpha$ method (starting on September 25, 1963) but is not reported here.

\subsection{EXPERIMENT 5}

On October 2, 1963, a symmetric assembly of three 15 in. diameter, interacting, coaxial uranium metal cylinders with a nominal height of 1.625 in. was measured at delayed criticality. There were four measurements of the separation between the top and middle cylinder and eight measurements of the separation of the middle and lower cylinders. The average separation of the top and middle cylinder was $2.30658 \pm 0.0170 \mathrm{in}$., and the average separation between the middle and lower cylinder was $2.3222 \pm$ 0.0126 in. The makeup of the assembly is depicted in Figure 8, which shows the assembled configuration with the diaphragms for the upper- and lower-cylinder supports. This configuration would be the best for comparing calculated $\mathrm{k}_{\text {eff }}$ with measurements because there are no corrections to the system for their associated uncertainties. This comparison calculation should include the support structure, the air in the room, and the walls, floor, and ceiling of the experimental cell. The lower, middle, and upper cylinder of the experiment had masses of $87,757,87,897$, and $88,069 \mathrm{~g}$, respectively, for a total uranium metal mass of $263,723 \mathrm{~g}$. The presence of the support structure consisting of the diaphragms, diaphragm support rings, and the lower support stand was evaluated. In some cases, the reactivity was measured, and in others only the change in separation was measured. Without these supports, the separation of the middle and lower cylinder would have been 0.0507 in. closer (i.e., 2.2715 in.). The reactivity change associated with a change in separation of the middle and lower cylinder was measured at 0.707 cents/mil. Without the air in the cell and the cell structure, the separation would have been lower yet. The measured height of the various sections of the upper and lower cylinder, the sum of the measured heights of the individual parts, and the difference from which the average air gap between parts that composed the central 7 in. diameter section and the various annuli are given in Table 10. These gaps should be included in the detailed model when comparing calculations with measurements. 
Table 10. Measured height of each radial increment, sum of inspection report heights, and average gap between parts of each radial section for experiment 5 with three interacting $15 \mathrm{in}$. OD cylinders that are 1.625 in. high.

\begin{tabular}{|c|c|c|c|c|c|c|}
\hline \multirow{2}{*}{ Cylinder } & \multirow{2}{*}{ Quantity } & \multicolumn{5}{|c|}{$\begin{array}{c}\text { Measured heights, sum of part thicknesses, and gaps(mils) for } \\
\text { radial thicknesses of }\end{array}$} \\
\hline & & 7 in. OD & $\begin{array}{l}7 \text { in. ID- } \\
9 \text { in. OD }\end{array}$ & $\begin{array}{l}9 \text { in. ID- } \\
11 \text { in. OD }\end{array}$ & $\begin{array}{l}11 \text { in. ID- } \\
13 \text { in. OD }\end{array}$ & $\begin{array}{l}13 \text { in. ID- } \\
15 \text { in. OD }\end{array}$ \\
\hline \multirow{4}{*}{ Upper } & Measured height (in.) & 1.6273 & 1.6234 & 1.6235 & 1.6255 & 1.6230 \\
\hline & Sum of part thicknesses (in.) & 1.62375 & 1.6206 & 1.62525 & 1.62715 & 1.6135 \\
\hline & Number of gaps & 3 & 3 & 3 & 4 & 3 \\
\hline & Average gap (mils) & 1.2 & 0.9 & 0 & 0 & 2.4 \\
\hline \multirow{4}{*}{ Middle } & Measured height (in.) & 1.6236 & 1.6207 & 1.623 & 1.6217 & 1.6227 \\
\hline & Sum of part thicknesses (in.) & 1.62129 & 1.61954 & 1.61834 & 1.62164 & 1.62104 \\
\hline & Number of gaps & 3 & 3 & 3 & 3 & 4 \\
\hline & Average gap (mils) & 0.8 & 0.4 & 1.5 & 0.0 & 0.4 \\
\hline \multirow{4}{*}{ Lower } & Measured height (in.) & $\mathrm{NM}^{\mathrm{a}}$ & NM & NM & NM & NM \\
\hline & Sum of part thicknesses (in.) & 1.6276 & 1.6243 & 1.62665 & 1.6286 & 1.6230 \\
\hline & Number of gaps & 1 & 1 & 1 & 2 & 2 \\
\hline & Average gap (mils) ${ }^{b}$ & 0.1 & 2.9 & 0.9 & 0.35 & 2.2 \\
\hline
\end{tabular}

${ }^{a} \mathrm{NM}$ means not measured.

bUsed values from experiment with 1.75 in. high cylinders. 


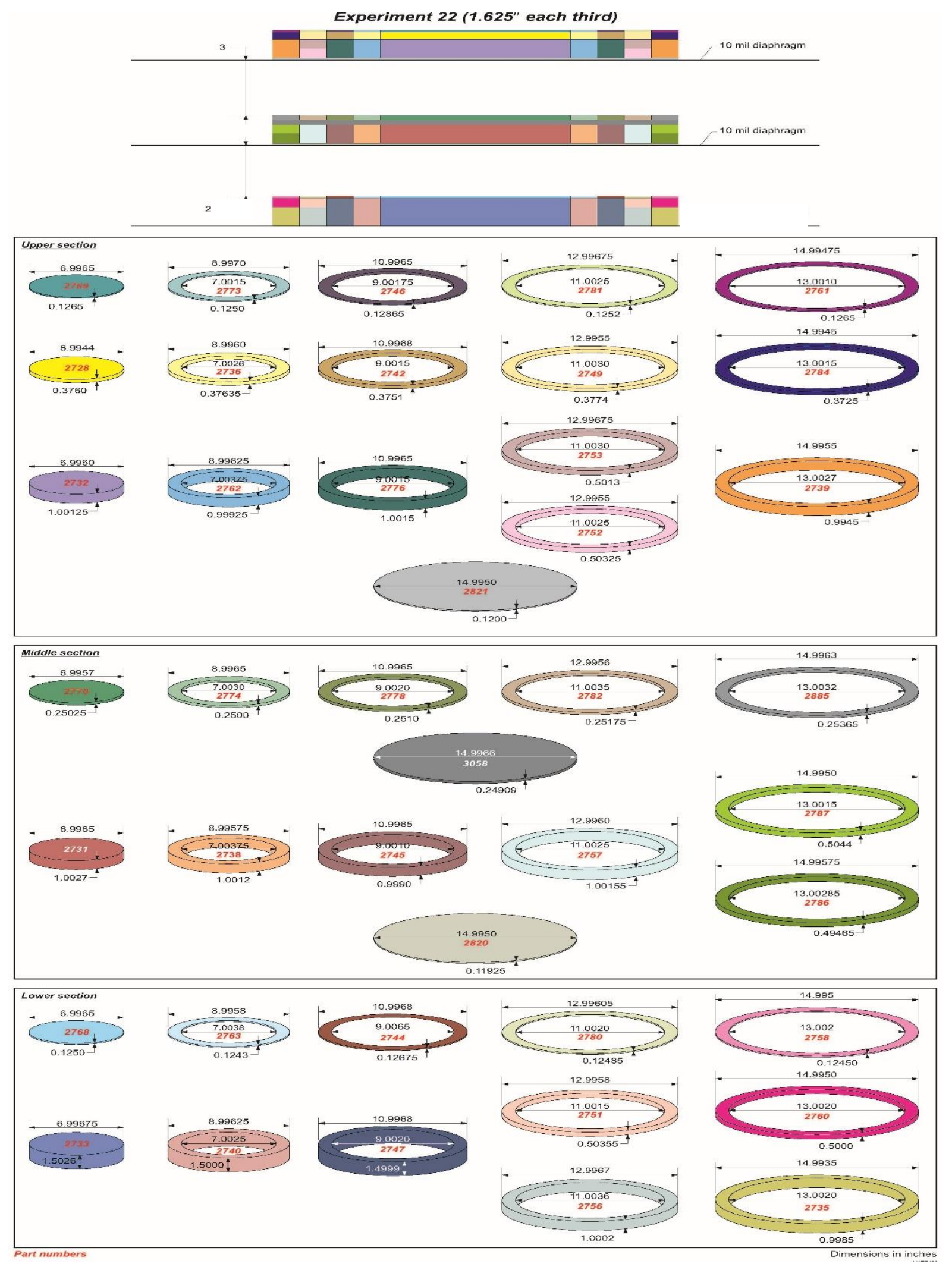

Figure 8. Experiment 5-Configuration of delayed critical unreflected, unmoderated uranium (93.14 wt.\% ${ }^{235} \mathrm{U}$ ) metal $15 \mathrm{in}$. diameter three interacting cylinders with nominal height of $1.625 \mathrm{in}$. (configuration drawing provided by John Bess of Idaho National laboratory) 
The effects of room return should be calculated by Monte Carlo simulations assuming the wall and floor were $2 \mathrm{ft}$ thick. The concrete can be assumed to be Oak Ridge concrete, which used crushed limestone instead of sand in the aggregate. For this calculation $2 \mathrm{ft}$. is adequate because neutrons penetrating more that have little chance of getting back to the assembly. In summary the configurations for experiment 5 and the $\mathrm{k}_{\text {eff }}$ values are given in Table 11 .

Table 11 Summary of configurations and neutron multiplication factors for experiment 5.

\begin{tabular}{|l|c|c|}
\hline \multicolumn{1}{|c|}{ Configuration } & $\begin{array}{c}\text { Spacing } \\
\text { (in.) }\end{array}$ & $\begin{array}{c}\text { Neutron } \\
\text { multiplication } \\
\text { factor } \\
\text { (k }\end{array}$ \\
\hline Witf $)$ \\
correction for room return & $2.3065,2.3097$ & 1.00000 \\
& $2.27220^{\mathrm{b}}$ & \\
& $2.3370,2.3087$ & \\
$2.3212^{\mathrm{b}}$ & \\
& $2.3251,2.3135$ & \\
& 2.3175. & \\
& $2.3251,2.3201$ & \\
$2.2900^{\mathrm{b}}$ & \\
& Average top-to-middle \\
& $2.30658 \pm 0.01702$ & \\
\hline Without support structure, no & Average middle-to-bottom & 1.00000 \\
correction for room return & $2.32220 \pm 0.01262$ & \\
\hline
\end{tabular}

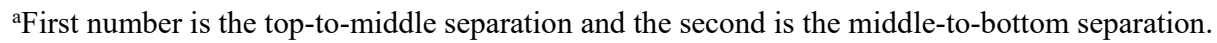
All measurements are included in this table with average values and $\mathrm{k}_{\text {eff }}$ was 1.0000 for all measurement.

${ }^{\mathrm{b}}$ The numbers are additional measurements of the separation of the middle and lower sections.

In addition, the prompt neutron decay constant at delayed criticality was measured using the Rossi- $\alpha$ method (August 28, 1963) but is not reported here.

\subsection{EXPERIMENT 6}

On August 30, 1963, a symmetric assembly of three 15 in. diameter, interacting, coaxial uranium metal cylinders with a nominal height of 1.75 in. was measured at delayed criticality with a separation distance of $2.8982 \mathrm{in}$. between the upper and middle cylinder and a separation of $2.88485 \mathrm{in}$. between the middle and the lower cylinder. The makeup of the assembly is depicted in Figure 9, which shows the assembled configuration with the diaphragms for the upper- and lower-cylinder supports. This configuration would be the best for comparing calculated $\mathrm{k}_{\text {eff }}$ with measurements because there are no corrections to the system for their associated uncertainties. This comparison calculation should include the support structure, the air in the room, and the walls, floor, and ceiling of the experimental cell. The lower, middle, and upper cylinder of the experiment had masses of 94,595, 94,532, and 94,912 g, respectively, for a total uranium metal mass of $284,039 \mathrm{~g}$. The presence of the support structure consisting of the diaphragms, diaphragm support rings, and the lower support stand was evaluated. In some cases, the reactivity was measured, and in others only the change in separation was measured. Without these supports, the separation of the middle and lower cylinder would have been 0.0512 in. closer (i.e., 2.83365 in.). Without the air in the cell and the cell structure, the separation would have been lower yet. The measured height of the various sections of the upper and lower cylinder, the sum of the measured heights of the individual parts, and the difference from which the average air gap between parts that composed the central 7 in. diameter section 
and the various annuli are given in Table 12. These gaps should be included in the detailed model when comparing calculations with measurements.

Table 12. Measured height of each radial increment, sum of inspection report heights, and average gap between parts of each radial section for experiment 6 with three interacting 15 in. OD cylinders that are 1.75 in. high.

\begin{tabular}{|c|c|c|c|c|c|c|}
\hline \multirow{2}{*}{ Cylinder } & \multirow{2}{*}{ Quantity } & \multicolumn{5}{|c|}{$\begin{array}{c}\begin{array}{c}\text { Measured heights, sum of part thicknesses, and gaps (mils) for } \\
\text { radial thicknesses of }\end{array}\end{array}$} \\
\hline & & 7 in. OD & $\begin{array}{l}7 \text { in. ID- } \\
9 \text { in. OD }\end{array}$ & $\begin{array}{l}9 \text { in. ID- } \\
11 \text { in. OD }\end{array}$ & $\begin{array}{l}11 \text { in. ID- } \\
13 \text { in. OD }\end{array}$ & $\begin{array}{l}13 \text { in. ID- } \\
15 \text { in. OD }\end{array}$ \\
\hline \multirow{4}{*}{ Upper } & Measured height (in.) & 1.7577 & 1.7521 & 1.7481 & 1.7504 & 1.7516 \\
\hline & Sum of part thicknesses (in.) & 1.74704 & 1.74589 & 1.74244 & 1.74534 & 1.74209 \\
\hline & Number of gaps & 3 & 3 & 3 & 3 & 4 \\
\hline & Average gap (mils) & 3.6 & 2.1 & 1.9 & 1.7 & 2.4 \\
\hline \multirow{4}{*}{ Middle } & Measured height (in.) & 1.7487 & 1.7463 & 1.751 & 1.753 & 1.7485 \\
\hline & Sum of part thicknesses (in.) & 1.74155 & 1.7393 & 1.7465 & 1.752 & 1.73845 \\
\hline & Number of gaps & 4 & 4 & 4 & 5 & 3 \\
\hline & Average gap (mils) & 1.8 & 1.75 & 1.1 & 0.2 & 3.3 \\
\hline \multirow{4}{*}{ Lower } & Measured height (in.) & 1.7529 & 1.7529 & 1.7518 & 1.7562 & 1.7566 \\
\hline & Sum of part thicknesses (in.) & 1.75285 & 1.750 & 1.7509 & 1.7555 & 1.75215 \\
\hline & Number of gaps & 1 & 1 & 1 & 2 & 2 \\
\hline & Average gap (mils) & 0.1 & 2.9 & 0.9 & 0.35 & 2.2 \\
\hline
\end{tabular}



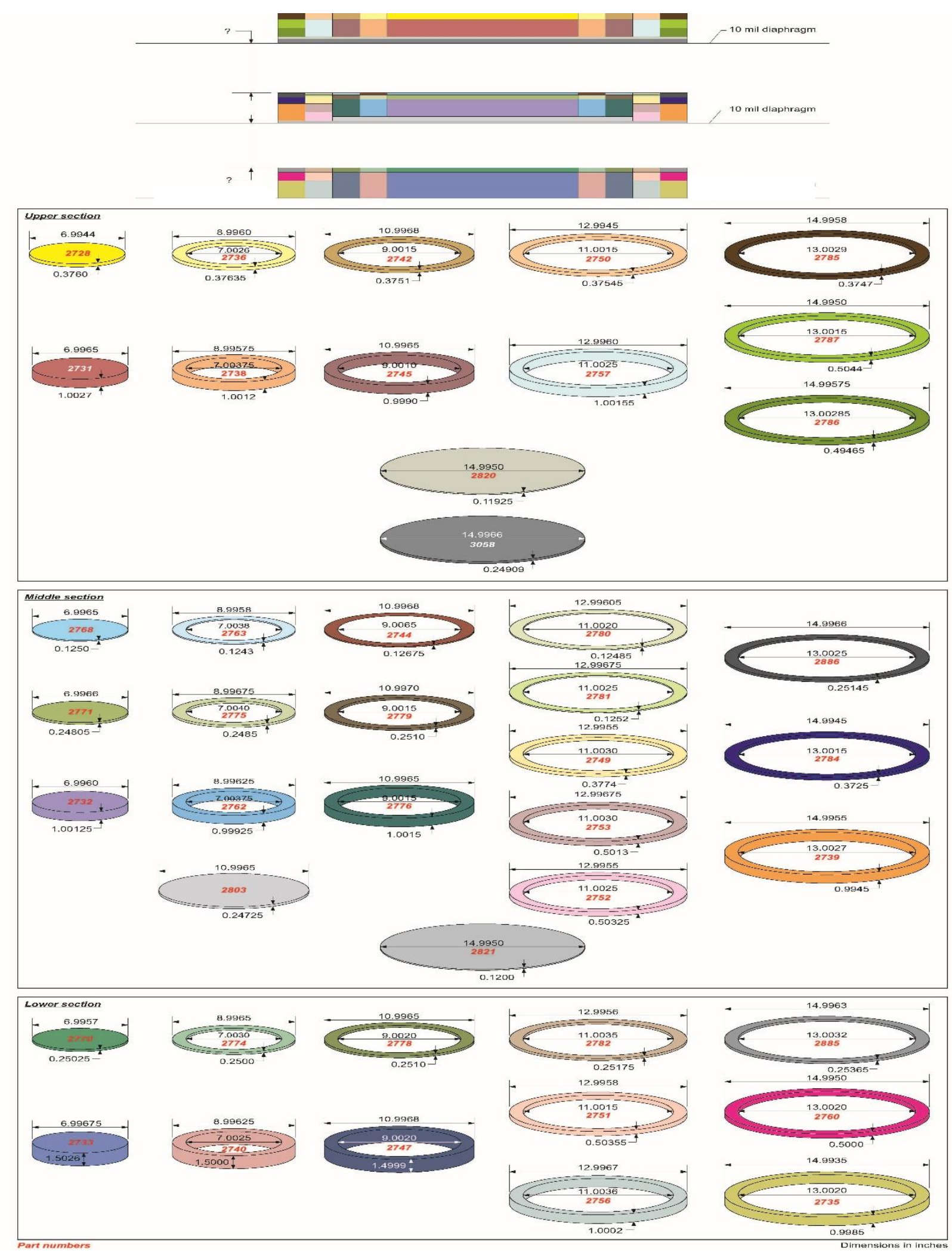

Figure 9. Experiment 6-Configuration of delayed critical unreflected, unmoderated uranium (93.14 wt.\% ${ }^{235} \mathrm{U}$ ) metal 15 in. diameter three interacting cylinders with a nominal height of 1.75 in. (configuration drawing provided by John Bess of Idaho National laboratory) 
The effects of room return should be calculated by Monte Carlo simulations assuming the wall and floor were $2 \mathrm{ft}$ thick. The concrete can be assumed to be Oak Ridge concrete, which used crushed limestone instead of sand in the aggregate. For this calculation $2 \mathrm{ft}$. is adequate because neutrons penetrating more that have little chance of getting back to the assembly. In summary the configurations for experiment 6 and the $\mathrm{k}_{\text {eff }}$ values are given in Table 13 .

Table 13. Summary of configurations and neutron multiplication factors for experiment 6.

\begin{tabular}{|l|c|c|}
\hline \multicolumn{1}{|c|}{ Configuration } & \multicolumn{1}{|c|}{$\begin{array}{c}\text { Spacinga } \\
\text { (in.) }\end{array}$} & $\begin{array}{c}\text { Neutron } \\
\text { multiplication } \\
\text { factor } \\
\left.\text { (k } \text { eff }^{\mathbf{a}}\right)\end{array}$ \\
\hline $\begin{array}{l}\text { With support structure, no correction for } \\
\text { room return }\end{array}$ & $2.8982,2.88485$ & 1.00000 \\
\hline $\begin{array}{l}\text { Without support structure, no correction } \\
\text { for room return }\end{array}$ & $2.8982,2.83365$ & 1.00000 \\
\hline
\end{tabular}

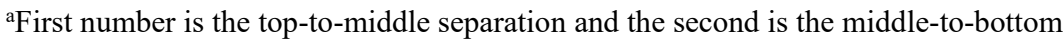
separation.

In addition, the prompt neutron decay constant at delayed criticality was measured using the Rossi- $\alpha$ method (starting on September 3, 1963) but is not reported here.

\subsection{EXPERIMENT 7}

On September 4, 1963, a symmetric assembly of three 15 in. diameter, interacting coaxial uranium metal cylinders with a nominal height of 1.875 in. was measured at delayed criticality with a separation distance of $3.5378 \mathrm{in}$. between the upper and middle cylinder and a separation of $3.5285 \mathrm{in}$. between the middle and the lower cylinder. The makeup of the assembly is depicted in Figure 10, which shows the assembled configuration with the diaphragms for the upper- and lower-cylinder supports. This configuration would be the best for comparing calculated $\mathrm{k}_{\text {eff }}$ with measurements because there are no corrections to the system for their associated uncertainties. This comparison calculation should include the support structure, the air in the room, and the walls, floor, and ceiling of the experimental cell. The lower, middle, and upper cylinder of the experiment had masses of 101,430,101,330, and 101,613 g, respectively, for a total uranium metal mass of $304,373 \mathrm{~g}$. The presence of the support structure consisting of the diaphragms, diaphragm support rings, and the lower support stand was evaluated. In some cases, the reactivity was measured, and in others only the change in separation was measured. Without these supports, the separation of the middle and lower cylinder would have been 0.0552 in. closer (i.e., 3.4733 in.). The reactivity change associated with a change in separation of the middle and lower cylinder was measured at 0.44 cents/mil. Without the air in the cell and the cell structure, the separation would have been lower yet. The measured height of the various sections of the upper and lower cylinder, the sum of the measured heights of the individual parts, and the difference from which the average air gap between parts that composed the central 7 in. diameter section and the various annuli are given in Table 14. These gaps should be included in the detailed model when comparing calculations with measurements. 
Table 14. Measured height of each radial increment, sum of inspection report heights, and average gap between parts of each radial section for experiment 7 with three interacting $15 \mathrm{in}$. OD cylinders that are 1.875 in. high.

\begin{tabular}{|c|c|c|c|c|c|c|}
\hline \multirow{2}{*}{ Cylinder } & \multirow{2}{*}{ Quantity } & \multicolumn{5}{|c|}{$\begin{array}{c}\text { Measured heights, sum of part thicknesses, and gaps(mils) for } \\
\text { radial thicknesses of }\end{array}$} \\
\hline & & 7 in. OD & $\begin{array}{l}7 \text { in. ID- } \\
9 \text { in. OD }\end{array}$ & $\begin{array}{l}9 \text { in. ID- } \\
11 \text { in. OD }\end{array}$ & $\begin{array}{l}11 \text { in. ID- } \\
13 \text { in. OD }\end{array}$ & $\begin{array}{l}13 \text { in. ID- } \\
15 \text { in. OD }\end{array}$ \\
\hline \multirow{4}{*}{ Upper } & Measured height (in.) ${ }^{\mathrm{a}}$ & 1.8726 & 1.8787 & 1.8758 & 1.8814 & 1.8801 \\
\hline & Sum of part thicknesses (in.) & 1.86999 & 1.86864 & 1.86834 & 1.87349 & 1.86739 \\
\hline & Number of gaps & 2 & 2 & 2 & 3 & 4 \\
\hline & Average gap (mils) & 1.3 & 5.0 & 3.7 & 2.6 & 3.2 \\
\hline \multirow{4}{*}{ Middle } & Measured height (in.) & 1.8692 & 1.8713 & 1.8740 & 1.8826 & 1.8749 \\
\hline & Sum of part thicknesses (in.) & 1.86680 & 1.8650 & 1.87075 & 1.8789 & 1.86295 \\
\hline & Number of gaps & 4 & 4 & 4 & 5 & 4 \\
\hline & Average gap (mils) & 0.6 & 1.6 & 0.81 & 0.7 & 3.0 \\
\hline \multirow{4}{*}{ Lower } & Measured height (in.) & 1.8810 & 1.8812 & 1.8785 & 1.8823 & 1.8790 \\
\hline & Sum of part thicknesses (in.) & 1.8786 & 1.87635 & 1.8750 & 1.8792 & 1.8732 \\
\hline & Number of gaps & 1 & 1 & 1 & 2 & 2 \\
\hline & Average gap (mils) & 2.4 & 4.8 & 3.5 & 1.55 & 2.6 \\
\hline
\end{tabular}



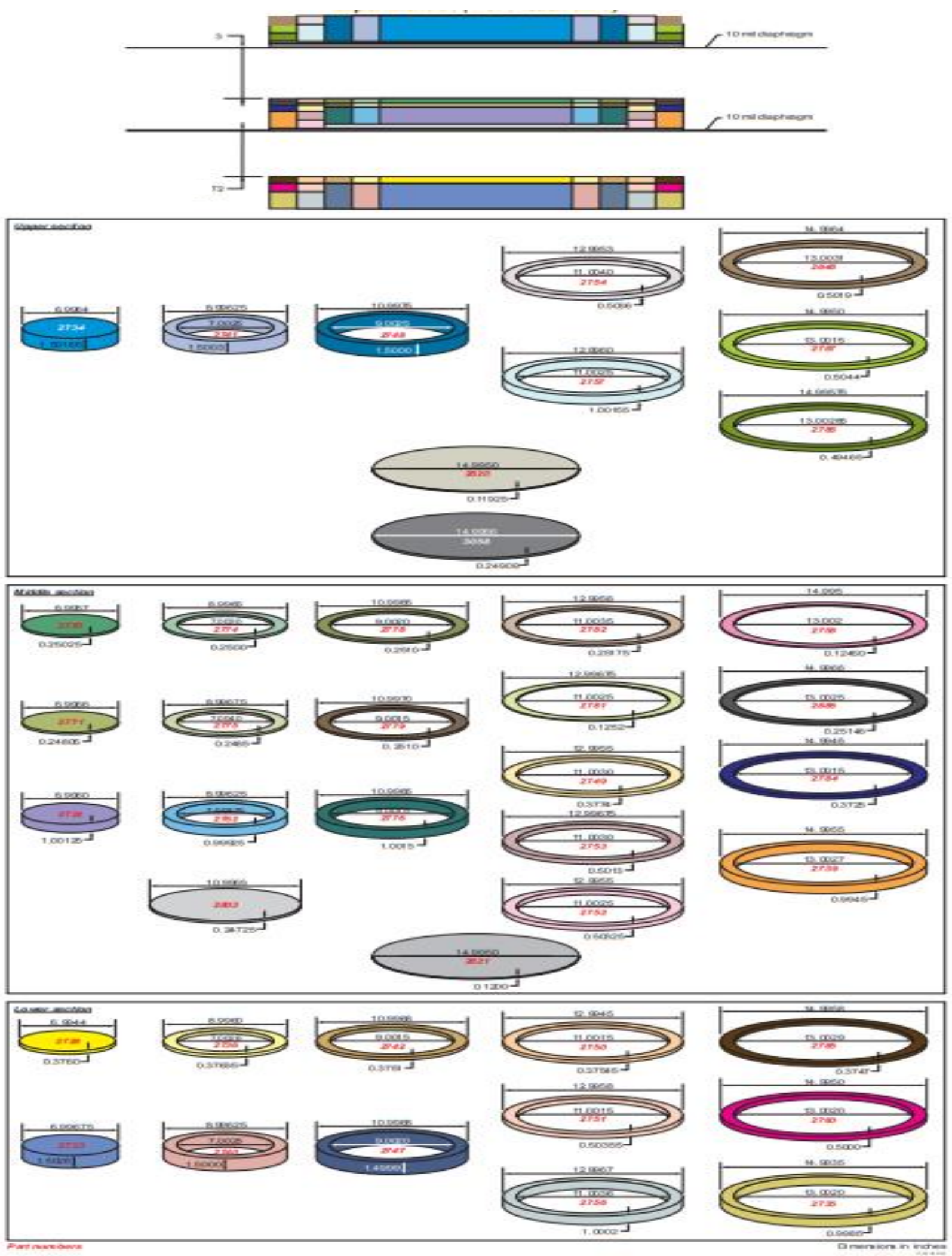

Figure 10. Experiment 7-Configuration of delayed critical unreflected, unmoderated uranium (93.14 wt.\%

${ }^{235} \mathrm{U}$ ) metal $15 \mathrm{in}$. diameter three interacting cylinders with a nominal height of $1.875 \mathrm{in}$. (configuration drawing provided by John Bess of Idaho National laboratory) 
The effects of room return should be calculated by Monte Carlo simulations assuming the wall and floor were $2 \mathrm{ft}$ thick. The concrete can be assumed to be Oak Ridge concrete, which used crushed limestone instead of sand in the aggregate. For this calculation $2 \mathrm{ft}$. is adequate because neutrons penetrating more that have little chance of getting back to the assembly. In summary the configurations for experiment 7 and the $\mathrm{k}_{\text {eff }}$ values are given in Table 15 .

Table 15. Summary of configurations and neutron multiplication factors for experiment 7.

\begin{tabular}{|l|c|c|}
\hline \multicolumn{1}{|c|}{ Configuration } & $\begin{array}{c}\text { Spacing } \\
\text { (in.) }\end{array}$ & $\begin{array}{c}\text { Neutron } \\
\text { multiplication } \\
\text { factor } \\
\left(\mathbf{k}_{\text {eff }}\right)\end{array}$ \\
\hline With support structure, no correction & $3.5378,3.5198$ & 1.00000 \\
for room return & $3.5285,3.5335$ & 1.00000 \\
\hline Without support structure, no & $3.5378,3.4676$ & 1.00000 \\
correction for room return & $3.5285,3.4783$ & 1.00000 \\
\hline
\end{tabular}

${ }^{a}$ First number is the top-to-middle separation and the second is the middle-to-bottom separation. The second set of numbers it the result of repeat measurements.

In addition, the prompt neutron decay constant at delayed criticality was measured using the Rossi- $\alpha$ method (September 9, 1963) but is not reported here.

\subsection{EXPERIMENT 8}

On September 12, 1963, a symmetric assembly of three 15 in. diameter, interacting coaxial uranium metal cylinders with a nominal height of $2.0 \mathrm{in}$. was measured at delayed criticality with a separation distance of $4.2477 \mathrm{in}$. between the upper and middle cylinder and a separation of $4.24985 \mathrm{in}$. between the middle and the lower cylinder. The makeup of the assembly is depicted in Figure 11. Because there was no drawing in the logbook, this postulated configuration is based on the limited number of uranium metal parts that were not in the assembly with $1.875 \mathrm{in}$. high cylinders that could be used to assemble the 2 in. thick cylinders. In the previous configuration, the next system assembled was a minimal change to the previous configuration because this resulted in less handling of uranium metal parts. Because of the limited number of $13 \mathrm{in.} \mathrm{ID-15} \mathrm{in.}$ OD parts, the height of the middle section was $\sim 0.060 \mathrm{in}$. more than $2 \mathrm{in}$. for the assembled configuration with the support structure. For some of the radial sections nearly all of the available uranium metal material for a given radial increment was in this assembly. This configuration would be the best for comparing calculated $\mathrm{k}_{\text {eff }}$ with measurements because there are no corrections to the system with their associated uncertainties. This comparison calculation should include the support structure, the air in the room, and the walls, floor, and ceiling of the experimental cell. The lower, middle, and upper cylinder of the experiment had masses of 108,233, 108,076, and 108,542 $\mathrm{g}$, respectively, for a total uranium metal mass of $324,851 \mathrm{~g}$. The presence of the support structure consisting of the diaphragms, diaphragm support rings, and the lower support stand was evaluated by measuring the change in the spacing of the middle and lower cylinder. Without these supports, the separation of the middle and lower cylinder would have been 0.0686 in. closer (i.e., 4.18125 in.). The reactivity change associated with a change in separation of the middle and lower cylinder was measured at $0.31 \mathrm{cents} / \mathrm{mil}$. Without the air in the cell and the cell structure, the separation would have been lower yet. The height of the various radial sections of the cylinders was not measured. Because these cylinders were mostly composed of the materials in the three interacting cylinders with a thickness of 1.875 in., the gaps between parts were assumed to be the same as for the $1.875 \mathrm{in}$. thick cylinders. These gaps are given in Table 16 and should be included in the detailed model when comparing calculations with measurements. 
Table 16. Assumed average gaps between part of each radial section for the three interacting $2.0 \mathrm{in}$. high cylinders.

\begin{tabular}{|c|c|c|c|c|c|c|}
\hline \multirow{2}{*}{ Cylinder } & \multirow{2}{*}{ Quantity } & \multicolumn{5}{|c|}{$\begin{array}{l}\text { Measured heights, sum of part thicknesses, and gaps(mils) for } \\
\text { radial thicknesses of }\end{array}$} \\
\hline & & 7 in. OD & $\begin{array}{l}7 \text { in. ID- } \\
9 \text { in. OD }\end{array}$ & $\begin{array}{l}9 \text { in. ID- } \\
11 \text { in. OD }\end{array}$ & $\begin{array}{l}11 \text { in. ID- } \\
13 \text { in. OD }\end{array}$ & $\begin{array}{l}13 \text { in. ID- } \\
15 \text { in. OD }\end{array}$ \\
\hline Upper & Average gap (mils) & 1.3 & 5.0 & 3.7 & 2.6 & 3.3 \\
\hline Middle & Average gap (mils) & 0.6 & 1.6 & 0.81 & 0.7 & 3.0 \\
\hline Lower & Average gap (mils) & 2.4 & 4.8 & 3.5 & 1.55 & 2.9 \\
\hline
\end{tabular}



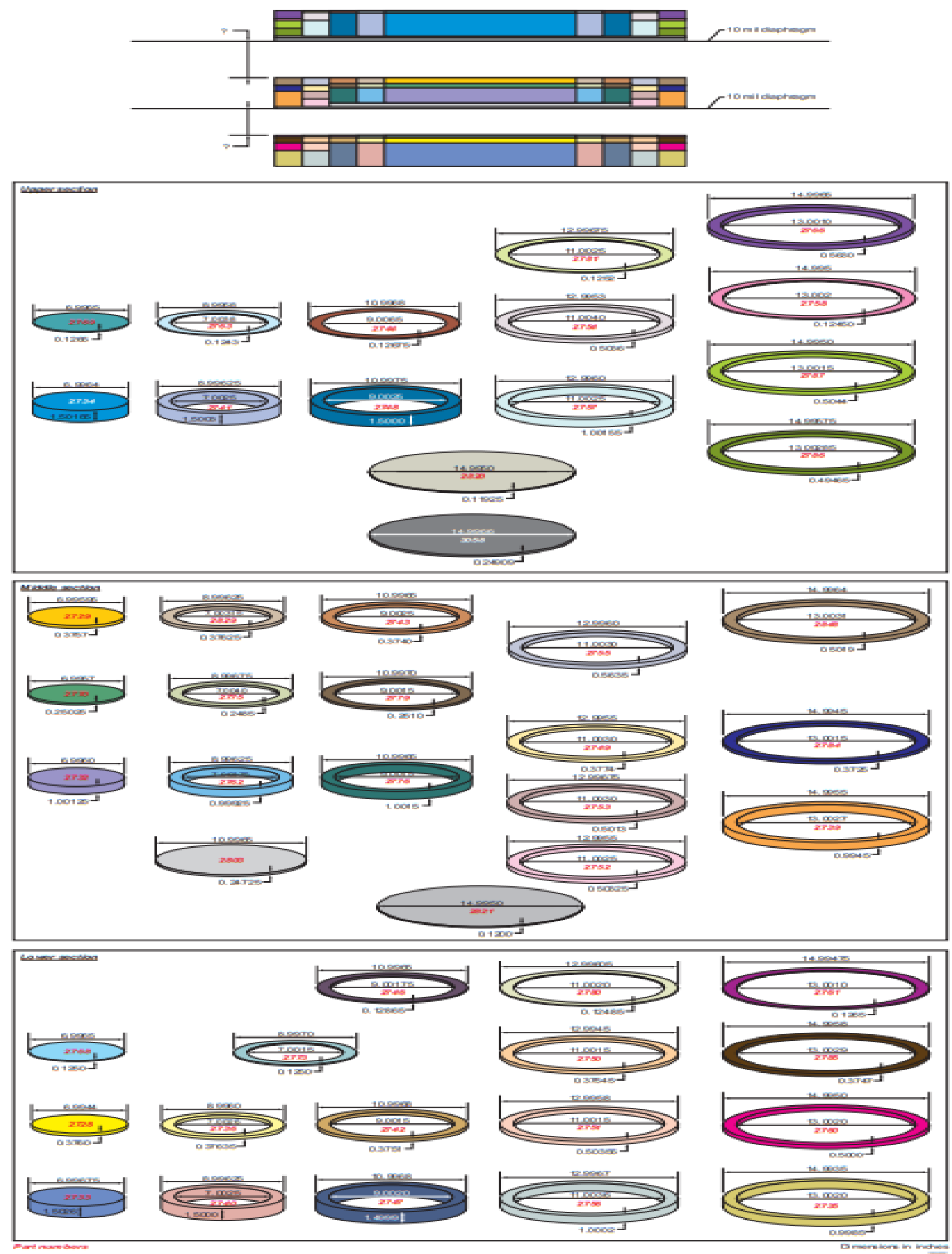

Figure 11. Experiment 8-Configuration of delayed critical unreflected, unmoderated uranium (93.14 wt.\% ${ }^{235} \mathrm{U}$ ) metal 15 in. diameter three interacting cylinders with a nominal height of $2.0 \mathrm{in}$. (configuration drawing provided by John Bess of Idaho National laboratory) 
The effects of room return should be calculated by Monte Carlo simulations assuming the wall and floor were $2 \mathrm{ft}$ thick. The concrete can be assumed to be Oak Ridge concrete, which used crushed limestone instead of sand in the aggregate. For this calculation $2 \mathrm{ft}$. is adequate because neutrons penetrating more that have little chance of getting back to the assembly. In summary the configurations for experiment 8 and the $\mathrm{k}_{\text {eff }}$ values are given in Table 17.

Table 17. Summary of configurations and neutron multiplication factors for experiment 8.

\begin{tabular}{|l|c|c|}
\hline \multicolumn{1}{|c|}{ Configuration } & $\begin{array}{c}\text { Spacing } \\
\text { (in.) }\end{array}$ & $\begin{array}{c}\text { Neutron } \\
\text { multiplication } \\
\text { factor }\end{array}$ \\
\hline $\begin{array}{l}\text { With support structure, no correction } \\
\text { for room return }\end{array}$ & $4.2477,4.24985$ & 1.00000 \\
\hline $\begin{array}{l}\text { Without support structure, no } \\
\text { correction for room return }\end{array}$ & $4.2477,4.18125$ & 1.00000 \\
\hline
\end{tabular}

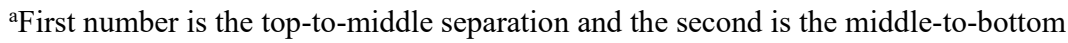
separation.

In addition, the prompt neutron decay constant at delayed criticality was measured using the Rossi- $\alpha$ method (starting on September 12, 1963) but is not reported here.

\section{DESCRIPTION OF MATERIAL DATA}

The set of cylinders and annuli were machined from highly enriched uranium metal of nominal density of $18.75 \mathrm{~g} / \mathrm{cm}^{3}$ and impurity content of $489 \mathrm{ppm}$. The solid cylinders had a nominal diameter of $7 \mathrm{in}$. and were fabricated with varying heights up to $1.5 \mathrm{in}$. The masses were measured at the Y-12 NSC to within $1 \mathrm{~g}$ with an uncertainty of $\pm 0.5 \mathrm{~g}$. The dimensions were measured to tenths of thousandths of inches with an uncertainty of $\pm 0.00005 \mathrm{in}$. The uranium isotopics were measured by spectrographic analysis, and the uncertainty on the ${ }^{234} \mathrm{U},{ }^{235} \mathrm{U}$, and ${ }^{236} \mathrm{U}$ isotopic content was \pm 0.005 wt.\%. The ${ }^{238} \mathrm{U}$ content was obtained by the difference from unity.

The average isotopic content of the parts from mass spectrographic analysis are $93.141 \mathrm{wt} . \%{ }^{235} \mathrm{U}$, $0.966 \mathrm{wt} . \%{ }^{234} \mathrm{U}$, and $0.244 \mathrm{wt} . \%{ }^{236} \mathrm{U}$. The impurity content was measured by spectrographic analysis with an average impurity content of $489 \mathrm{ppm} w \mathrm{wt} \%$. This value is very close to the quoted typical value for cast uranium metal (93.20 wt.\% ${ }^{235} \mathrm{U}$ enriched) at the Oak Ridge Y-12 NSC: $99.95 \mathrm{~g}$ of U per $100 \mathrm{~g}$ of material with an average impurity content of 500 ppm wt.\% [8].

The masses, dimensions, impurity content, and isotopic content are given in Tables 18-20. The average density in parenthesis from Table 18 weighted by the mass of each part is $18.747 \mathrm{~g} / \mathrm{cm}^{3}$. The isotopic analysis of one $7 \mathrm{in}$. diameter disc was not available. Each uranium metal part has a part number scribed on one flat surface of the annuli or cylinder for identification, which was also used for orientation of parts in an assembly. The surface of the part with the scribed number was the upper surface for all parts in all assemblies. The numbers given in the tables for the part numbers are the last four digits of the part numbers. The first six digits were the same for all part numbers and were used to identify uranium metal parts for ORCEF.

The data in Table 20 are the measured impurity content for the uranium metal used in the all experiments with uranium metal discs and annuli. Eleven randomly sampled cylinder/annuli parts were analyzed. Only average and range information exists [4]. The value assumed at this time for oxygen and nitrogen were 20 ppm for both, and these values were assumed to be for the $7 \mathrm{in}$. diameter discs. The values for carbon at 
this time (early 1960s) were much lower than present day values, which have added carbon from recasting the material many times.

Some recently discovered data from Y-12 NSC inspection reports for 37 HEU metal parts showed that the mass for each part was measured three times, and the dimensions were measured at three different locations for each part. The uranium isotopics were usually measured by dividing a metal chip from the machining process into thirds and performing isotopic analysis on each third. These data are not available for all parts. The masses measured were rounded to grams, and in no case for these 37 parts did the three mass measurements differ by more than $1 \mathrm{~g}$. The heights listed in the table were measured to one-tenth of a thousandth. The height measured at three different locations on the parts to $\pm 0.0001 \mathrm{in}$. was the same at all locations for $98 \%$ of the parts. Consequently, the heights are known to half of a ten thousandth of an inch. The outside diameters for the three measurements for each individual part were identical for more than $80 \%$ of the parts, which differed by 0.00005 in.

The isotopic enrichments are measured to $0.01 \mathrm{wt} . \%$ and thus are known to $\pm 0.005 \mathrm{wt} . \%$. The weight percent of ${ }^{235} \mathrm{U}$ for the three measurements of each individual part was identical for more than $95 \%$ of the parts, and it only differed by $0.02 \mathrm{wt} . \%$. The weight percent of ${ }^{234} \mathrm{U}$ for the three measurements for each individual part was identical for all 37 parts measured. The weight percent of ${ }^{234} U$ for the three measurements for each individual part was identical except for 3 of the 37 parts, and it differed by $0.02 \mathrm{wt} \%$ for two parts and $0.05 \mathrm{wt} \%$ for the other. Although these data are not available for the parts used in these measurements, the accuracies are expected to be similar.

Table 18. Average dimensions of uranium $\left(93.14 \mathrm{wt} . \%{ }^{235} \mathrm{U}\right)$ metal cylinders and annuli for delayed critical experiments with three 15 in. diameter interacting cylinders.

\begin{tabular}{|c|c|c|c|c|}
\hline $\begin{array}{c}\text { Part } \\
\text { number }\end{array}$ & $\begin{array}{c}\text { Measured } \\
\text { mass (g) }\end{array}$ & $\begin{array}{c}\text { Measured height } \\
\text { (in.) }\end{array}$ & $\begin{array}{c}\text { Measured inner } \\
\text { diameter } \\
\text { (in.) }\end{array}$ & $\begin{array}{c}\text { Measured outer } \\
\text { diameter } \\
\text { (in.) }\end{array}$ \\
\hline 2728 & 4,435 & 0.3760 & - & 6.9944 \\
\hline 2729 & 4,440 & 0.3757 & - & 6.99595 \\
\hline 2730 & 6,646 & 0.5620 & - & 6.9960 \\
\hline 2731 & 11,841 & 1.0027 & - & 6.9965 \\
\hline 2732 & 11,814 & 1.00125 & - & 6.9960 \\
\hline 2733 & 17,742 & 1.5026 & 13.0020 & 6.99675 \\
\hline 2734 & 17,742 & 1.50165 & 7.0026 & 6.9964 \\
\hline 2735 & 13,409 & 0.9985 & 7.0015 & 14.9935 \\
\hline 2736 & 2,895 & 0.37635 & 7.00375 & 8.9960 \\
\hline 2737 & 4,336 & 0.5625 & $1.0027(13.00265)$ & 8.9965 \\
\hline 2738 & 7,710 & 1.0012 & 7.0025 & 14.9955 \\
\hline 2739 & 13,461 & 0.9945 & 7.0025 & 8.99625 \\
\hline 2740 & 11,568 & 1.5000 & 9.0015 & 8.9965 \\
\hline 2741 & 11,568 & 1.5003 & 9.0025 & $10.9968(10.99675)$ \\
\hline 2742 & 3,617 & 0.3751 & 9.0065 & 10.99665 \\
\hline 2743 & 3,621 & 0.3740 & 9.0010 & 10.9965 \\
\hline 2744 & 1,223 & 0.12675 & 9.00175 & 10.9965 \\
\hline 2745 & 9,634 & 0.9990 & 9.0020 & $10.9968(10.99675)$ \\
\hline 2746 & 1,238 & 0.12865 & 9.0025 & 10.9975 \\
\hline 2747 & 14,436 & 1.4999 & 11.0030 & 12.9955 \\
\hline 2748 & 14,462 & 1.5000 & 11.0015 & 12.9945 \\
\hline 2749 & 4,360 & 0.3774 & 1.0015 & $12.9957(12.99575)$ \\
\hline 2750 & 4,336 & 0.37545 & & - \\
\hline 2751 & 5,822 & 0.50355 & - & \\
\hline
\end{tabular}


Table 18. Average dimensions of uranium $\left(93.14 \mathrm{wt} . \%{ }^{235} \mathrm{U}\right)$ metal cylinders and annuli for delayed critical experiments with three 15 in. diameter interacting cylinders (continued).

\begin{tabular}{|c|c|c|c|c|}
\hline $\begin{array}{c}\text { Part } \\
\text { number }\end{array}$ & $\begin{array}{l}\text { Measured } \\
\text { mass }(g)\end{array}$ & $\begin{array}{l}\text { Measured height } \\
\text { (in.) }\end{array}$ & $\begin{array}{l}\text { Measured inner } \\
\text { diameter } \\
\text { (in.) }^{\mathrm{a}}\end{array}$ & $\begin{array}{l}\text { Measured outer } \\
\text { diameter } \\
\text { (in.) }^{\mathrm{a}}\end{array}$ \\
\hline 2752 & 5,811 & 0.50325 & 11.0025 & 12.9955 \\
\hline 2753 & 5,872 & 0.50130 & 11.0030 & 12.99675 \\
\hline 2754 & 5,826 & 0.5036 & 11.0040 & 12.9953 \\
\hline 2755 & 6,514 & 0.5635 & 11.0030 & $12.9960(12.99595)$ \\
\hline 2756 & 11,567 & 1.0002 & 11.0036 & 12.9967 \\
\hline 2757 & 11,575 & 1.00155 & 11.0025 & 12.9960 \\
\hline 2758 & 1,685 & 0.1245 & 12.9965 & 14.99665 \\
\hline 2760 & 6,743 & 0.5000 & 13.0020 & 14.9950 \\
\hline 2761 & $1,706^{\mathrm{a}}$ & 0.1265 & 13.0010 & 14.99475 \\
\hline 2762 & $7,703^{\mathrm{a}}$ & 0.99925 & 7.00375 & 8.99625 \\
\hline 2763 & $953^{\mathrm{a}}$ & 0.1243 & 7.0038 & 8.9958 \\
\hline 2766 & $7,605^{\mathrm{a}}$ & 0.5630 & 13.0010 & 14.9965 \\
\hline 2767 & 5,410 & 0.5620 & 9.0010 & 10.99595 \\
\hline 2768 & 1,481 & 0.1250 & - & 6.9965 \\
\hline 2769 & 1,495 & $0.1265(.1259 ?)$ & - & 6.9965 \\
\hline 2770 & 2,955 & 0.25025 & - & 6.9957 \\
\hline 2771 & 2,916 & 0.24805 & - & 6.9966 \\
\hline 2773 & 962 & $\begin{array}{c}0.12567 \\
(0.125,0.126,0.126)\end{array}$ & 7.0015 & 8.9970 \\
\hline 2774 & 1,930 & 0.2500 & 7.0030 & 8.9965 \\
\hline 2775 & 1,917 & 0.2485 & 7.0040 & 8.99675 \\
\hline 2776 & 9,644 & 1.0015 & 9.0015 & 10.9965 \\
\hline 2778 & 2,411 & 0.2510 & 9.0020 & 10.9965 \\
\hline 2779 & 2,417 & 0.2510 & 9.0015 & 10.9970 \\
\hline 2780 & 1,440 & 0.12485 & 11.0020 & $12 . .99605$ \\
\hline 2781 & 1,449 & 0.1252 & 11.0025 & 12.99675 \\
\hline 2782 & 2,914 & 0.25175 & 11.0035 & 12.9956 \\
\hline 2783 & 2,900 & 0.25075 & 11.0030 & 12.9956 \\
\hline 2784 & 5,039 & 0.3725 & 13.0015 & 14.9945 \\
\hline 2785 & 5,043 & 0.3747 & $13.0029(13.00285)$ & $14.9958(14.99575)$ \\
\hline 2786 & 6,717 & 0.49965 & 13.0015 & 14.9950 \\
\hline 2787 & 6,788 & 0.5055 & 13.0015 & 14.9950 \\
\hline 2803 & 7,220 & 0.24725 & - & 10.9965 \\
\hline 2820 & 6,471 & 0.11925 & - & 14.9950 \\
\hline 2821 & 6,518 & 0.1200 & - & 14.9950 \\
\hline 2829 & 2,895 & 0.37625 & 7.00315 & 8.99625 \\
\hline 2848 & 6,748 & 0.5019 & 13.0031 & 14.9964 \\
\hline 2885 & 3,415 & 0.25365 & 13.0032 & 14.9963 \\
\hline 2886 & 3,384 & 0.25145 & 13.0025 & 14.9966 \\
\hline 3058 & 13,533 & 0.24909 & - & 14.9966 \\
\hline 3078 & 10,959 & 0.3753 & - & 10.9965 \\
\hline 0104 & 16,865 & 0.3109 & - & 14.99505 \\
\hline
\end{tabular}

${ }^{\text {a }}$ When one value is given, the same value was measured at three different locations. When a value is given in and out of parentheses, the value outside was measured twice. When three values are given, each one was measured once. 
Table 19. Summary of average uranium isotopics of metal cylinders and annuli, for delayed critical experiments with three 15 in. diameter interacting cylinders. ${ }^{a}$

\begin{tabular}{|c|c|c|c|c|}
\hline $\begin{array}{c}\text { Part } \\
\text { number }\end{array}$ & $\begin{array}{c}\text { Measured }{ }^{235} U \\
(\text { wt.\%) }\end{array}$ & $\begin{array}{c}\text { Measured }{ }^{234} \mathrm{U} \\
\text { (wt.\%) }\end{array}$ & $\begin{array}{c}\text { Measured }{ }^{236} \mathrm{U} \\
\text { (wt.\%) }\end{array}$ & $\begin{array}{c}{ }^{238} U^{b} \\
\text { (wt.\%) } \\
\end{array}$ \\
\hline 2728 & 93.17 & 0.97 & 0.24 & 5.62 \\
\hline 2729 & 93.15 & 0.99 & 0.26 & 5.60 \\
\hline 2730 & 93.14 & 0.97 & 0.25 & 5.64 \\
\hline 2731 & 93.13 & 0.97 & 0.22 & 5.68 \\
\hline 2732 & 93.17 & 0.95 & 0.21 & 5.67 \\
\hline 2733 & 93.15 & 0.96 & 0.26 & 5.63 \\
\hline 2734 & 93.18 & 0.95 & 0.24 & 5.63 \\
\hline 2735 & 93.12 & 0.98 & 0.25 & 5.65 \\
\hline 2736 & 93.17 & 1.01 & 0.21 & 5.61 \\
\hline 2737 & 93.08 & 0.99 & 0.29 & 5.64 \\
\hline 2738 & 93.15 & 0.98 & 0.24 & 5.63 \\
\hline 2739 & 93.16 & 0.96 & 0.25 & 5.63 \\
\hline 2740 & 93.17 & 0.97 & 0.24 & 5.62 \\
\hline 2741 & 93.18 & 0.96 & 0.25 & 5.61 \\
\hline 2742 & 93.14 & 0.98 & 0.23 & 5.65 \\
\hline 2743 & 93.14 & 0.98 & 0.23 & 5.65 \\
\hline 2744 & 93.14 & 0.98 & 0.23 & 5.65 \\
\hline 2745 & 93.20 & 0.96 & 0.22 & 5.62 \\
\hline 2746 & 93.09 & 1.00 & 0.22 & 5.69 \\
\hline 2747 & 93.16 & 0.98 & 0.19 & 5.67 \\
\hline 2748 & 93.09 & 1.00 & 0.22 & 5.69 \\
\hline 2749 & 93.19 & 0.98 & 0.25 & 5.58 \\
\hline 2750 & 93.12 & 0.95 & 0.25 & 5.68 \\
\hline 2751 & 93.13 & 0.98 & 0.24 & 5.65 \\
\hline 2752 & 93.13 & 0.98 & 0.24 & 5.65 \\
\hline 2753 & 93.12 & 0.95 & 0.25 & 5.68 \\
\hline 2754 & 93.10 & 0.96 & 0.28 & 5.66 \\
\hline 2755 & 93.10 & 0.96 & 0.28 & 5.66 \\
\hline 2756 & 93.18 & 0.93 & 0.25 & 5.64 \\
\hline 2757 & 93.20 & 0.96 & 0.23 & 5.61 \\
\hline 2758 & 93.16 & 0.98 & 0.27 & 5.59 \\
\hline 2760 & 93.13 & 0.99 & 0.24 & 5.64 \\
\hline 2761 & 93.12 & 0.96 & 0.27 & 5.65 \\
\hline 2762 & 93.13 & 0.97 & 0.27 & 5.63 \\
\hline 2763 & 93.18 & 0.96 & 0.25 & 5.61 \\
\hline 2766 & 93.16 & 0.98 & 0.27 & 5.59 \\
\hline 2767 & 93.14 & 0.96 & 0.26 & 5.64 \\
\hline 2768 & 93.14 & 0.92 & 0.26 & 5.68 \\
\hline 2769 & 93.15 & 0.97 & 0.25 & 5.63 \\
\hline 2770 & 93.13 & 0.99 & 0.26 & 5.62 \\
\hline 2771 & Not available & Not available & Not available & Not available \\
\hline 2773 & 93.17 & 0.97 & 0.24 & 5.62 \\
\hline
\end{tabular}


Table 19. Summary of average uranium isotopics of metal cylinders and annuli, for delayed critical experiments with three 15 in. diameter interacting cylinders ${ }^{\text {a }}$ (continued).

\begin{tabular}{|c|c|c|c|c|}
\hline $\begin{array}{c}\text { Part } \\
\text { number }\end{array}$ & $\begin{array}{c}\text { Measured }{ }^{235} \mathrm{U} \\
(\text { wt.\%) }\end{array}$ & $\begin{array}{c}\text { Measured }{ }^{234} \mathrm{U} \\
(\text { wt.\%) }\end{array}$ & $\begin{array}{c}\text { Measured }{ }^{236} \mathrm{U} \\
(\text { wt.\%) }\end{array}$ & $\begin{array}{c}{ }^{238} \mathrm{U}^{\mathrm{b}} \\
\text { (wt.\%) }\end{array}$ \\
\hline 2774 & 93.08 & 0.99 & 0.29 & 5.64 \\
\hline 2775 & 93.15 & 0.98 & 0.24 & 5.61 \\
\hline 2776 & 93.16 & 0.96 & 0.23 & 5.65 \\
\hline 2778 & 93.16 & 0.96 & 0.23 & 5.65 \\
\hline 2779 & 93.16 & $0 / 96$ & 0.23 & 5.65 \\
\hline 2780 & 93.13 & 0.98 & 0.25 & 5.58 \\
\hline 2781 & 93.19 & 0.98 & 0.25 & 5.58 \\
\hline 2782 & 93.20 & 0.96 & 0.23 & 5.61 \\
\hline 2783 & 93.18 & 0.93 & 0.25 & 5.64 \\
\hline 2784 & 93.13(93.11,93.13,93.11) & 0.99 & $0.24(0.26,0.24,0.26)$ & 5.64 \\
\hline 2785 & $93.11(93.14,93.11,93.14)$ & $0.99(0.98,0.99,0.98)$ & $0.26(0.24,0.26,0.24)$ & 5.64 \\
\hline 2786 & 93.14 & 0.98 & 0.24 & 5.64 \\
\hline 2787 & 93.14 & 0.98 & 0.24 & 5.64 \\
\hline 2803 & 93.14 & 1.00 & 0.23 & 5.63 \\
\hline 2820 & 93.18 & 0.96 & 0.25 & 5.61 \\
\hline 2821 & 93.31 & & & \\
\hline 2829 & 93.10 & 0.99 & 0.24 & 5.67 \\
\hline 2848 & 93.18 & 0.99 & 0.24 & 5.59 \\
\hline 2885 & 93.11 & 0.99 & 0.26 & 5.64 \\
\hline 2886 & 93.11 & 0.99 & 0.26 & 5.64 \\
\hline 3058 & Not available (NA) ${ }^{c}$ & NA & NA & NA \\
\hline 3078 & NA & NA & NA & NA \\
\hline 0104 & NA & NA & NA & NA \\
\hline
\end{tabular}

${ }^{a}$ Mass spectrographic analysis. When one value is given it was measured three times. When three values are given in parentheses, each was measured once.

${ }^{\mathrm{b}}$ By difference from $100 \%$.

${ }^{c}$ Use average values.

Table 20. Measured impurity content of uranium metal cylinders and annuli for delayed critical experiments with three 15 in. diameter interacting cylinders. ${ }^{a}$

\begin{tabular}{|c|c|c|}
\hline Element & $\begin{array}{c}\text { Parts per million by weight } \\
\text { (ppm) }\end{array}$ & $\begin{array}{c}\text { Range } \\
\text { (ppm) }\end{array}$ \\
\hline $\mathrm{Ag}$ & 8 & $3-25$ \\
\hline $\mathrm{Bi}$ & 164 & $81-311$ \\
\hline $\mathrm{C}$ & 5 & $0-9$ \\
\hline $\mathrm{Co}$ & 5 & $2-15$ \\
\hline $\mathrm{Cr}$ & 7 & $4-12$ \\
\hline $\mathrm{Cu}$ & 25 & $10-40$ \\
\hline $\mathrm{Mg}$ & 3 & $2-3$ \\
\hline $\mathrm{Mn}$ & 56 & $25-89$ \\
\hline $\mathrm{N}$ & 30 & - \\
\hline
\end{tabular}


Table 20. Measured impurity content of uranium metal cylinders and annuli for delayed critical experiments with three 15 in. diameter interacting cylinders ${ }^{a}$ (continued).

\begin{tabular}{|c|c|c|}
\hline Element & $\begin{array}{c}\text { Parts per million by weight } \\
\text { (ppm) }\end{array}$ & $\begin{array}{c}\text { Range } \\
\text { (ppm) }\end{array}$ \\
\hline $\mathrm{Na}$ & 27 & $15-50$ \\
\hline $\mathrm{Ni}$ & 100 & - \\
\hline $\mathrm{O}$ & 20 & - \\
\hline $\mathrm{Sb}$ & 38 & $10-80$ \\
\hline $\mathrm{Ti}$ & 1 & - \\
\hline
\end{tabular}

${ }^{a}$ Mass spectrographic analysis, except nitrogen and oxygen which is assumed to be $20 \mathrm{ppm}$.

\section{SUPPLEMENTAL EXPERIMENTAL MEASUREMENTS}

Supplemental experimental Rossi- $\alpha$ measurements were performed and are not reported here [9]. These data and the logbook can be acquired from Laboratory Records at ORNL or John Bess at Idaho National Laboratory. To access these data use site https://doi.ccs.ornl.gov/ui/doi/86. These Rossi- $\alpha$ measurements are unique in that the flight time across the gaps between cylinders is a large part of the neutron lifetime and depends strongly on the energy spectrum of neutrons going between interacting cylinders.

\section{CONCLUSIONS}

These accurate descriptions of the configuration and materials allow these experiments to be incorporated into the International Criticality Safety Benchmark Program (ICSBEP). Uncertainty analyses need to be performed to determine the accuracy of the neutron multiplication factors $\left(\mathrm{k}_{e f f}\right)$. These analyses should mimic those performed for other ICSBEP nuclear criticality safety benchmarks already documented with these materials in the ICSBEP and Nuclear Energy Agency programs such as HEU-MET-FAST-051 and others. Because of the accurate descriptions of the configuration and material, the uncertainties in the $\mathrm{k}_{\text {eff }}$ values should be as low as \pm 0.0002 .

\section{REFERENCES}

1. J. T. Mihalczo, Brief Summary of Unreflected and Unmoderated Cylindrical Critical Experiments with Oralloy at Oak Ridge, ORNL/TM-1999/302, Lockheed Martin Energy Research Inc., Oak Ridge National Laboratory (November 1999).

2. J. T. Mihalczo, "Prompt-Neutron Decay in a Two-Component Enriched Uranium Metal Critical Assembly,” Trans. Am. Nucl. Soc. 6, 60 (1963).

3. J. T. Mihalczo, Prompt Neutron Decay in a Two-Component Enriched Uranium Metal Critical Assembly, ORNL/TM-470, Union Carbide Nuclear Corporation, Oak Ridge National Laboratory, Oak Ridge, TN (1963).

4. J. T. Mihalczo, Graphite and Polyethylene Reflected Uranium-Metal Cylinders and Annuli, Y-DR-81, Union Carbide Corporation Nuclear Division, Oak Ridge Y-12 Plant (1972).

5. J. T. Mihalczo, Prompt Neutron Lifetime in Critical Enriched-Uranium Metal Cylinders and Annuli, Nucl. Sci. Eng. 20, 60-65 (1964). 
6. J. T. Mihalczo, "Monte Carlo Calculations of Two Core Delayed Critical Assemblies," Trans. Am. Nucl. Soc. 11, 603 (1968).

7. J. T. Mihalczo, "Prompt Neutron Time Behavior in Delayed Critical Coupled Uranium Metal Cylinders," Proceedings of the International Conference on Fast Critical Experiments and Their Analysis, ANL-7320, 237-241 (October 1966).

8. Mihalczo, J.T.; Lynn, J.J.; Taylor, J.R.; Hansen, G.E.; Pelowitz, D.B., “Delayed Critical ORNL Unreflected Uranium (93.20) Metal Sphere and the Pure Unreflected Uranium (93.80) Sphere Critical Mass," Annals of Nuclear Energy, v 29, n 5, March 2002, p 525-560 (2002).

9. John T. Mihalczo, "Data from Rossi- $\alpha$ and Pulsed Neutron Prompt neutron Time Decay Measurements at ORCEF" Oak Ridge national Laboratory, ORNL/TM-2019/1455 (April 2019) 


\section{APPENDIX A. SUPPORT STRUCTURE}

The support structure is described in this appendix. Figure A.1 represents the diaphragm and rings with its support structure. Figure A.2 represents the low-mass support structure. Both structures can be seen in Figure 2. These support structures were used in many other critical experiments with uranium metal at the Oak Ridge Critical Experiments Facility.

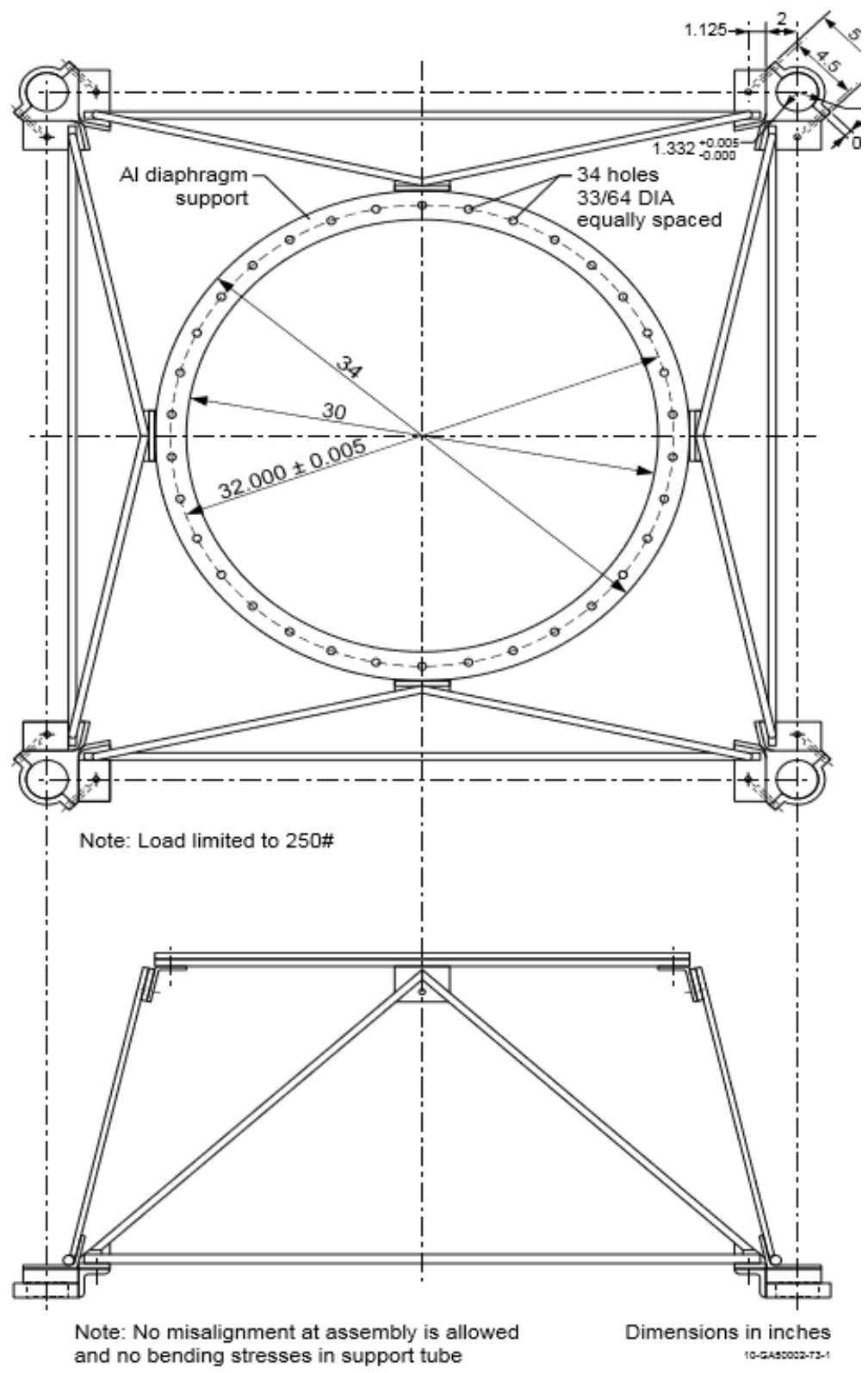

Figure A.1. Diaphragm support structure. 


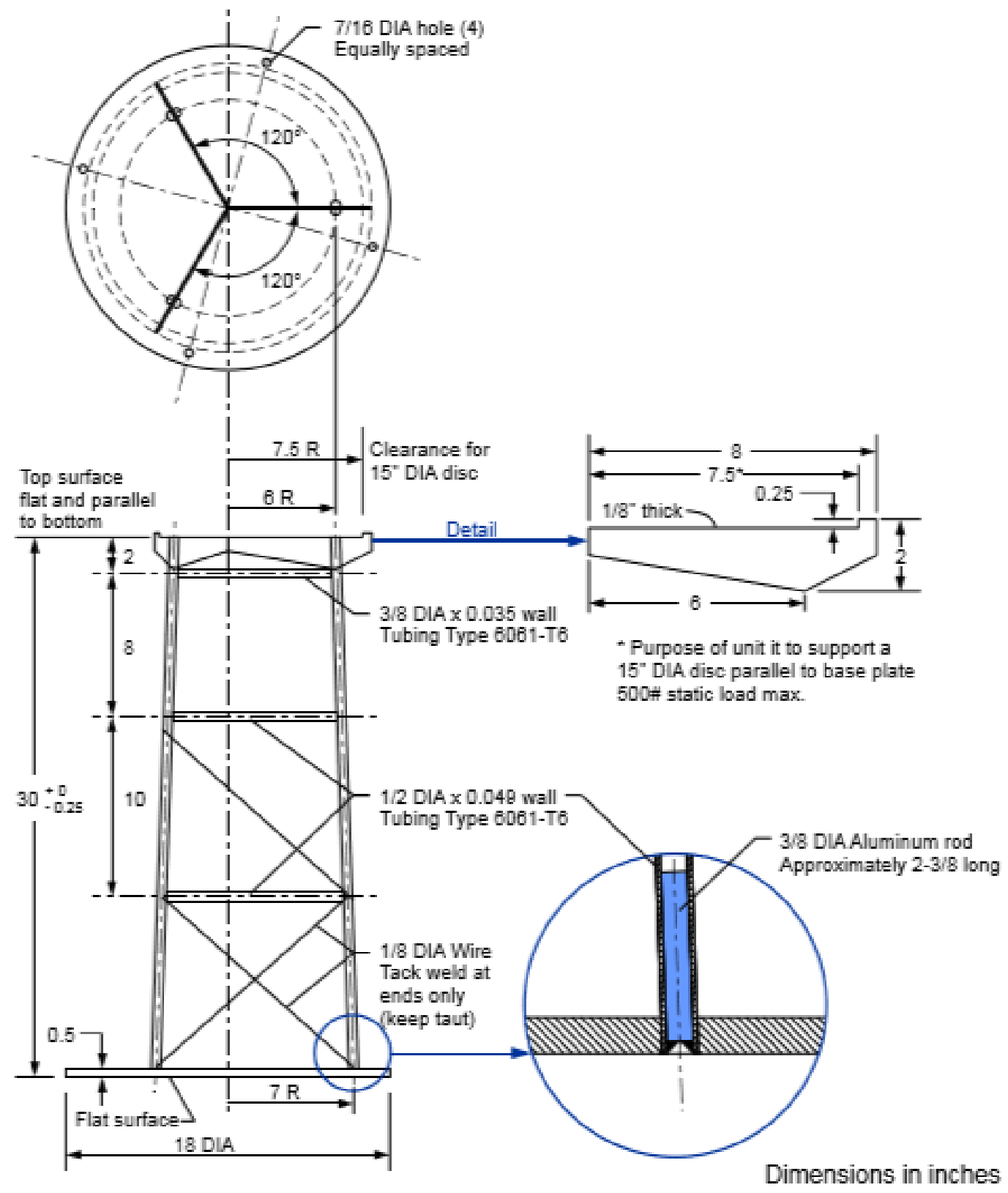

Figure A.2. Details of the lower support structure 


\section{APPENDIX B. UNCERTAINTIES IN MATERIALS PROVIDED BY THE Y-12 NSC}

The uncertainties in the masses, dimension, and uranium isotopics measured at the Y-12 National Security Complex are discussed in the following reference.

John T. Mihalczo, Uncertainties in Masses, Dimensions, Impurities, and Isotopics of HEU Metal Used in Critical Experiments at ORCEF, ORNL/TM-2012/32, Oak Ridge National Laboratory, Oak Ridge, TN (September 2012). [OSTI \#1052246]

Some recently discovered data from Y-12 National Security Complex inspection reports for highly enriched uranium metal parts are provided in Table B.1. For some parts, only two results were available. The data in this appendix are the results of individual measurements of these quantities. The mass for each part was measured three times; the dimensions were measured at three different locations for each part; and the uranium isotopics were measured usually by dividing a metal chip from the machining process into thirds and performing isotopic analysis on each third. These data are not available for all parts, and for some parts, only two results are presented. The masses measured were rounded to grams, and in no case for these 37 parts did the mass differ for the three individual measurements. The heights listed in the table were all measured to one-tenth of a thousandth, but zeros after the decimal are not listed. For example, where the entry of the table is given as 1.5 , the measured value was $1.5000 \mathrm{in}$. The height measured at three different locations on the parts to $\pm 0.0001 \mathrm{in}$. was the same at all locations for all but 1 of 37 parts. Consequently, the heights are known to half of a ten thousandth of an inch.

The inside diameters for the three measurements for each individual part were identical except for 3 of the 37 parts. In two cases they differed by 0.00005 in. and in the other case by 0.0001 in. The outside diameters for the three measurements for each individual part were identical except for 6 of the 37 parts, which differed by 0.00005 in.

The isotopic enrichments are measured to $0.01 \mathrm{wt} . \%$ and thus are known to $\pm 0.005 \mathrm{wt} . \%$. The weight percent of ${ }^{235} \mathrm{U}$ for the three measurements for each individual part was identical except for 1 of the 37 parts, which differed by $0.02 \mathrm{wt} . \%$. The weight percent of ${ }^{234} \mathrm{U}$ for the three measurements for each individual part was identical for all 37 parts. The weight percent ${ }^{234} U$ for the three measurements for each individual part was identical except for three of the 37 parts, where it differed by $0.02 \mathrm{wt} . \%$ for two parts and $0.05 \mathrm{wt} . \%$ for the other.

Measured mass (g), dimension (in.), and uranium isotopics (wt.\%) from inspection reports are given in Table B.1.

Table B.1. Results of inspection reports for HEU metal parts.

\begin{tabular}{|c|c|c|c|c|c|c|c|c|c|}
\hline Test & Part & $\begin{array}{c}\text { Mass } \\
\text { (g) }\end{array}$ & $\begin{array}{c}\text { Height } \\
\text { (in.) }\end{array}$ & $\begin{array}{c}\text { ID } \\
\text { (in.) }\end{array}$ & $\begin{array}{c}\text { OD } \\
\text { (in.) }\end{array}$ & ${ }^{235} \mathbf{U}$ & ${ }^{234} \mathbf{U}$ & ${ }^{236} \mathbf{U}$ & ${ }^{238} \mathbf{U}$ \\
\hline HMF051 & 2735 & 13,409 & 0.9985 & 13.002 & 14.9935 & 93.12 & 0.98 & 0.25 & 5.65 \\
\hline HMF071 & & 13,409 & 0.9985 & 13.002 & 14.9935 & 93.12 & 0.98 & 0.25 & 5.65 \\
\hline HMF076 & & 13,409 & 0.9985 & 13.002 & 14.9935 & 93.12 & 0.98 & 0.25 & 5.65 \\
\hline HMF051 & 2736 & 2,895 & 0.37635 & 7.0026 & 8.996 & 93.17 & 1.01 & 0.21 & 5.61 \\
\hline HMF071 & & 2,895 & 0.37635 & 7.0026 & 8.996 & 93.17 & 1.01 & 0.21 & 5.61 \\
\hline HMF076 & & 2,895 & 0.37635 & 7.0026 & 8.996 & 93.17 & 1.01 & 0.21 & 5.61 \\
\hline HMF051 & 2737 & 4,336 & 0.5625 & 7.0015 & 8.9965 & 93.08 & 0.99 & 0.29 & 5.64 \\
\hline HMF071 & & 4,336 & 0.5625 & 7.0015 & 8.9965 & 93.08 & 0.99 & 0.29 & 5.64 \\
\hline
\end{tabular}


Table B.1. Results of inspection reports for HEU metal parts (continued).

\begin{tabular}{|c|c|c|c|c|c|c|c|c|c|}
\hline Test & Part & $\begin{array}{c}\text { Mass } \\
(\mathrm{g})\end{array}$ & $\begin{array}{c}\text { Height } \\
\text { (in.) }\end{array}$ & $\begin{array}{l}\text { ID } \\
\text { (in.) }\end{array}$ & $\begin{array}{l}\text { OD } \\
\text { (in.) }\end{array}$ & ${ }^{235} \mathrm{U}$ & ${ }^{234} \mathbf{U}$ & ${ }^{236} \mathbf{U}$ & ${ }^{238} \mathrm{U}$ \\
\hline HMF076 & & 4,336 & 0.5625 & 7.0015 & 8.9965 & 93.08 & 0.99 & 0.29 & 5.64 \\
\hline HMF051 & 2738 & 7,710 & 1.0012 & 7.00375 & 8.99575 & 93.15 & 0.98 & 0.24 & 5.63 \\
\hline HMF071 & & 7,710 & 1.0012 & 7.00375 & 8.99575 & 93.15 & 0.98 & 0.24 & 5.63 \\
\hline HMF076 & & 7,710 & 1.0012 & 7.00375 & 8.99575 & 93.15 & 0.98 & 0.24 & 5.63 \\
\hline HMF051 & 2739 & 13,461 & 0.9945 & 13.0027 & 14.9955 & 93.16 & 0.96 & 0.25 & 5.63 \\
\hline HMF071 & & 13,461 & 0.9945 & 13.00265 & 14.9955 & 93.16 & 0.96 & 0.25 & 5.63 \\
\hline HMF076 & & 13,461 & 0.9945 & 13.0027 & 14.9955 & 93.16 & 0.96 & 0.25 & 5.63 \\
\hline HMF051 & 2740 & 11,568 & 1.5 & 7.0025 & 8.99625 & 93.17 & 0.97 & 0.24 & 5.62 \\
\hline HMF071 & & 11,568 & 1.5 & 7.0025 & 8.99625 & 93.17 & 0.97 & 0.24 & 5.62 \\
\hline HMF076 & & 11,568 & 1.5 & 7.0025 & 8.99625 & 93.17 & 0.97 & 0.24 & 5.62 \\
\hline HMF051 & 2742 & 3,617 & 0.3751 & 9.0015 & 10.9968 & 93.14 & 0.98 & 0.23 & 5.65 \\
\hline HMF071 & & 3,617 & 0.3751 & 9.0015 & 10.99675 & 93.14 & 0.98 & 0.23 & 5.65 \\
\hline HMF076 & & 3,617 & 0.3751 & 9.0015 & 10.9968 & 93.14 & 0.98 & 0.23 & 5.65 \\
\hline HMF051 & 2743 & 3,621 & 0.374 & 9.0025 & 10.9965 & 93.14 & 0.98 & 0.23 & 5.65 \\
\hline HMF071 & & 3,621 & 0.374 & 9.0025 & 10.9965 & 93.14 & 0.98 & 0.23 & 5.65 \\
\hline HMF076 & & 3,621 & 0.374 & 9.0025 & 10.9965 & 93.14 & 0.98 & 0.23 & 5.65 \\
\hline HMF051 & 2744 & 1,223 & 0.12675 & 9.0065 & 10.9968 & 93.14 & 0.98 & 0.23 & 5.65 \\
\hline HMF071 & & 1,223 & 0.12675 & 9.0065 & 10.99675 & 93.14 & 0.98 & 0.23 & 5.65 \\
\hline HMF076 & & 1,223 & 0.12675 & 9.0065 & 10.9968 & 93.14 & 0.98 & 0.23 & 5.65 \\
\hline HMF051 & 2745 & 9,634 & 0.999 & 9.001 & 10.9965 & 93.2 & 0.96 & 0.22 & 5.62 \\
\hline HMF071 & & 9,634 & 0.999 & 9.001 & 10.9965 & 93.2 & 0.96 & 0.22 & 5.62 \\
\hline HMF076 & & 9,634 & 0.999 & 9.001 & 10.9965 & 93.2 & 0.96 & 0.22 & 5.62 \\
\hline HMF051 & 2746 & 1,238 & 0.12865 & 9.00175 & 10.9965 & 93.09 & 1 & 0.22 & 5.69 \\
\hline HMF071 & & 1,238 & 0.12865 & 9.00175 & 10.9965 & 93.09 & 1 & 0.22 & 5.69 \\
\hline HMF076 & & 1,238 & 0.12865 & 9.00175 & 10.9965 & 93.09 & 1 & 0.22 & 5.69 \\
\hline HMF051 & 2747 & 14,436 & 1.4999 & 9.002 & 10.9968 & 93.16 & 0.98 & 0.19 & 5.67 \\
\hline HMF071 & & 14,436 & 1.4999 & 9.002 & 10.99675 & 93.16 & 0.98 & 0.19 & 5.67 \\
\hline HMF076 & & 14,436 & 1.4999 & 9.002 & 10.9968 & 93.16 & 0.98 & 0.19 & 5.67 \\
\hline HMF051 & 2748 & 14,462 & 1.5 & 9.0025 & 10.9975 & 93.09 & 1 & 0.22 & 5.69 \\
\hline HMF071 & & 14,462 & 1.5 & 9.0025 & 10.9975 & 93.09 & 1 & 0.22 & 5.69 \\
\hline HMF076 & & 14,462 & 1.5 & 9.0025 & 10.9975 & 93.09 & 1 & 0.22 & 5.69 \\
\hline HMF051 & 2749 & 4,360 & 0.3774 & 11.003 & 12.9955 & 93.19 & 0.98 & 0.25 & 5.58 \\
\hline HMF071 & & 4,360 & 0.3774 & 11.003 & 12.9955 & 93.19 & 0.98 & 0.25 & 5.58 \\
\hline HMF076 & & 4,360 & 0.3774 & 11.003 & 12.9955 & 93.19 & 0.98 & 0.25 & 5.58 \\
\hline HMF051 & 2750 & 4,336 & 0.37545 & 11.0015 & 12.9945 & 93.12 & 0.95 & 0.25 & 5.68 \\
\hline HMF071 & & 4,336 & 0.37545 & 11.0015 & 12.9945 & 93.12 & 0.95 & 0.25 & 5.68 \\
\hline HMF076 & & 4,336 & 0.37545 & 11.0015 & 12.9945 & 93.12 & 0.95 & 0.25 & 5.68 \\
\hline HMF051 & 2751 & 5,822 & 0.50355 & 11.0015 & 12.9958 & 93.13 & 0.98 & 0.24 & 5.65 \\
\hline
\end{tabular}


Table B.1. Results of inspection reports for HEU metal parts (continued).

\begin{tabular}{|c|c|c|c|c|c|c|c|c|c|}
\hline Test & Part & $\begin{array}{c}\text { Mass } \\
(\mathrm{g})\end{array}$ & $\begin{array}{c}\text { Height } \\
\text { (in.) }\end{array}$ & $\begin{array}{l}\text { ID } \\
\text { (in.) }\end{array}$ & $\begin{array}{l}\text { OD } \\
\text { (in.) }\end{array}$ & ${ }^{235} \mathbf{U}$ & ${ }^{234} \mathbf{U}$ & ${ }^{236} \mathbf{U}$ & ${ }^{238} \mathbf{U}$ \\
\hline HMF071 & & 5,822 & 0.50355 & 11.0015 & 12.99575 & 93.13 & 0.98 & 0.24 & 5.65 \\
\hline HMF076 & & 5,822 & 0.50355 & 11.0015 & 12.9958 & 93.13 & 0.98 & 0.24 & 5.65 \\
\hline HMF051 & 2752 & na & na & na & na & na & na & na & na \\
\hline HMF071 & & 5,811 & 0.50325 & 11.0025 & 12.9955 & 93.13 & 0.98 & 0.24 & 5.65 \\
\hline HMF076 & & 5,811 & 0.50325 & 11.0025 & 12.9955 & 93.13 & 0.98 & 0.24 & 5.65 \\
\hline HMF051 & 2753 & na & na & na & na & na & na & na & na \\
\hline HMF071 & & 5,782 & 0.5013 & 11.003 & 12.99675 & 93.12 & 0.95 & 0.25 & 5.69 \\
\hline HMF076 & & 5,782 & 0.5013 & 11.003 & 12.99675 & 93.12 & 0.95 & 0.28 & 5.66 \\
\hline HMF051 & 2754 & 5,826 & 0.5036 & 11.004 & 12.9953 & 93.1 & 0.96 & 0.28 & 5.66 \\
\hline HMF071 & & 5,826 & 0.5036 & 11.004 & 12.9953 & 93.1 & 0.96 & 0.28 & 5.66 \\
\hline HMF076 & & 5,826 & 0.5036 & 11.004 & 12.9953 & 93.1 & 0.96 & 0.28 & 5.66 \\
\hline HMF051 & 2755 & 6,514 & 0.5635 & 11.003 & 12.996 & 93.1 & 0.96 & 0.28 & 5.66 \\
\hline HMF071 & & 6,514 & 0.5635 & 11.003 & 12.99595 & 93.1 & 0.96 & 0.28 & 5.66 \\
\hline HMF076 & & 6,514 & 0.5635 & 11.003 & 12.996 & 93.1 & 0.96 & 0.28 & 5.66 \\
\hline HMF051 & 2756 & 11,567 & 1.0002 & 11.0036 & 12.9967 & 93.18 & 0.93 & 0.25 & 5.64 \\
\hline HMF071 & & 11,567 & 1.0002 & 11.0036 & 12.9967 & 93.18 & 0.93 & 0.25 & 5.64 \\
\hline HMF076 & & 11,567 & 1.0002 & 11.0036 & 12.9967 & 93.18 & 0.93 & 0.25 & 5.64 \\
\hline HMF051 & 2757 & 11,575 & 1.00155 & 11.0025 & 12.996 & 93.2 & 0.96 & 0.23 & 5.61 \\
\hline HMF071 & & 11,575 & 1.00155 & 11.0025 & 12.996 & 93.2 & 0.96 & 0.23 & 5.61 \\
\hline HMF076 & & 11,575 & 1.00155 & 11.0025 & 12.996 & 93.2 & 0.96 & 0.23 & 5.61 \\
\hline HMF051 & 2761 & na & na & na & na & na & na & na & na \\
\hline HMF071 & & 1,706 & 0.1265 & 13.001 & 14.99475 & 93.12 & 0.96 & 0.27 & 5.65 \\
\hline HMF076 & & 1,706 & 0.1265 & 13.001 & 14.99475 & 93.12 & 0.96 & 0.27 & 5.65 \\
\hline HMF051 & 2762 & 7,703 & 0.99925 & 7.00375 & 8.99625 & 93.13 & 0.97 & 0.27 & 5.63 \\
\hline HMF071 & & 7,703 & 0.99925 & 7.0037 & 8.99625 & 93.13 & 0.97 & 0.27 & 5.63 \\
\hline HMF076 & & 7,703 & 0.99925 & 7.00375 & 8.99625 & 93.13 & 0.97 & 0.27 & 5.63 \\
\hline HMF051 & 2763 & 953 & 0.1243 & 7.0038 & 8.9958 & 93.18 & 0.96 & 0.25 & 5.66 \\
\hline HMF071 & & 953 & 0.1243 & 7.0038 & 8.9958 & 93.18 & 0.96 & 0.25 & 5.61 \\
\hline HMF076 & & 953 & 0.1243 & 7.0038 & 8.9958 & 93.18 & 0.96 & 0.25 & 5.61 \\
\hline HMF051 & 2766 & 7,605 & 0.563 & 13.001 & 14.9965 & 93.16 & 0.98 & 0.27 & 5.59 \\
\hline HMF071 & & 7,605 & 0.563 & 13.001 & 14.9965 & 93.16 & 0.98 & 0.27 & 5.59 \\
\hline HMF076 & & 7,605 & 0.563 & 13.001 & 14.9965 & 93.16 & 0.98 & 0.27 & 5.59 \\
\hline HMF051 & 2773 & 962 & 0.125 & 7.0015 & 8.997 & 93.17 & 0.97 & 0.24 & 5.62 \\
\hline HMF071 & & 962 & 0.126 & 7.0015 & 8.997 & 93.17 & 0.97 & 0.24 & 5.62 \\
\hline HMF076 & & 962 & 0.126 & 7.0015 & 8.997 & 93.17 & 0.97 & 0.24 & 5.62 \\
\hline HMF051 & 2774 & 1,930 & 0.25 & 7.003 & 8.9965 & 93.08 & 0.99 & 0.24 & 5.69 \\
\hline HMF071 & & 1,930 & 0.25 & 7.003 & 8.9965 & 93.08 & 0.99 & 0.29 & 5.64 \\
\hline HMF076 & & 1,930 & 0.25 & 7.003 & 8.9965 & 93.08 & 0.99 & 0.29 & 5.64 \\
\hline HMF051 & 2775 & 1,917 & 0.2485 & 7.004 & 8.99675 & 93.15 & 0.98 & 0.24 & 5.63 \\
\hline HMF071 & & 1,917 & 0.2485 & 7.004 & 8.99675 & 93.15 & 0.98 & 0.24 & 5.63 \\
\hline
\end{tabular}


Table B.1. Results of inspection reports for HEU metal parts (continued).

\begin{tabular}{|c|c|c|c|c|c|c|c|c|c|}
\hline Test & Part & $\begin{array}{c}\text { Mass } \\
\text { (g) }\end{array}$ & $\begin{array}{c}\text { Height } \\
\text { (in.) }\end{array}$ & $\begin{array}{c}\text { ID } \\
\text { (in.) }\end{array}$ & $\begin{array}{c}\text { OD } \\
\text { (in.) }\end{array}$ & ${ }^{235} \mathbf{U}$ & ${ }^{234} \mathbf{U}$ & ${ }^{236} \mathbf{U}$ & ${ }^{238} \mathbf{U}$ \\
\hline HMF076 & & 1,917 & 0.2485 & 7.004 & 8.99675 & 93.15 & 0.98 & 0.24 & 5.63 \\
\hline HMF051 & 2776 & 9,644 & 1.0015 & 9.0015 & 10.9965 & 93.16 & 0.96 & 0.23 & 5.65 \\
\hline HMF071 & & 9,644 & 1.0015 & 9.0015 & 10.9965 & 93.16 & 0.96 & 0.23 & 5.65 \\
\hline HMF076 & & 9,644 & 1.0015 & 9.0015 & 10.9965 & 93.16 & 0.96 & 0.23 & 5.65 \\
\hline HMF051 & 2778 & 2,411 & 0.251 & 9.002 & 10.9965 & 93.16 & 0.96 & 0.23 & 5.65 \\
\hline HMF071 & & 2,411 & 0.251 & 9.002 & 10.9965 & 93.16 & 0.96 & 0.23 & 5.65 \\
\hline HMF076 & & 2,411 & 0.251 & 9.002 & 10.9965 & 93.16 & 0.96 & 0.23 & 5.65 \\
\hline HMF051 & 2779 & 2,417 & 0.251 & 9.0015 & 10.997 & 93.16 & 0.96 & 0.23 & 5.65 \\
\hline HMF071 & & 2,417 & 0.251 & 9.0015 & 10.997 & 93.16 & 0.96 & 0.23 & 5.65 \\
\hline HMF076 & & 2,417 & 0.251 & 9.0015 & 10.997 & 93.16 & 0.96 & 0.23 & 5.65 \\
\hline HMF051 & 2780 & na & na & na & na & na & na & na & na \\
\hline HMF071 & & 1,440 & 0.12485 & 11.002 & 12.99605 & 93.13 & 0.98 & 0.25 & 5.64 \\
\hline HMF076 & & 1,440 & 0.12485 & 11.002 & 12.99605 & 93.13 & 0.98 & 0.25 & 5.64 \\
\hline HMF071 & 2784 & 5,039 & 0.3725 & 13.0015 & 14.9945 & 93.13 & 0.99 & 0.24 & 5.64 \\
\hline HMF076 & & 5,039 & 0.3725 & 13.0015 & 14.9945 & 93.11 & 0.99 & 0.26 & 5.64 \\
\hline HMF051 & 2785 & 5,043 & 0.3747 & 13.0029 & 14.9958 & 93.14 & 0.98 & 0.24 & 5.64 \\
\hline HMF071 & & 5,043 & 0.3747 & 13.00285 & 14.99575 & 93.11 & 0.99 & 0.26 & 5.64 \\
\hline HMF076 & & 5,043 & 0.3747 & 13.0029 & 14.9958 & 93.14 & 0.98 & 0.24 & 5.64 \\
\hline HMF051 & 2829 & 2,895 & 0.37625 & 7.00315 & 8.99625 & 93.1 & 0.99 & 0.24 & 5.67 \\
\hline HMF071 & & 2,895 & 0.37625 & 7.00315 & 8.99625 & 93.1 & 0.99 & 0.24 & 5.67 \\
\hline HMF076 & & 2,895 & 0.37625 & 7.00315 & 8.99625 & 93.1 & 0.99 & 0.24 & 5.67 \\
\hline HMF051 & 2848 & 6,748 & 0.5019 & 13.0031 & 14.9964 & 93.18 & 0.99 & 0.24 & 5.66 \\
\hline HMF071 & & 6,748 & 0.5019 & 13.0031 & 14.9964 & 93.18 & 0.99 & 0.24 & 5.59 \\
\hline HMF076 & & 6,748 & 0.5019 & 13.0031 & 14.9964 & 93.18 & 0.99 & 0.24 & 5.59 \\
\hline
\end{tabular}

${ }^{a}$ na means not available 